\title{
El feminicidio: realidad o mentira dentro de la política pública colombiana
}

\author{
Marien Yolanda Correa-Corredor*, Noris Mendoza-Pérez ${ }^{\star *}$, Clara Milena Rincón-Guauque, \\ Yenny Marcela Arenas-Rueda, Erick Johann Aguilar-Noriega, José Eliecer Villamizar-Mendoza ${ }^{\star \star *}$
}

* Magíster en Relaciones Internacionales con énfasis en paz y conflicto, Universidad El Salvador, Buenos Aires, Argentina. Docente e Investigadora, Universidad Cooperativa de Colombia, sede Bucaramanga.

Correo electrónico: marien.correa@ucc.edu.co

** Profesora de la Facultad de Derecho de la Universidad Cooperativa de Colombia. Ex asesora temática de las mismas investigaciones.

Correo electrónico: noris.mendoza@campusucc.edu.co

*** Egresados graduados de la Facultad de Derecho de la Universidad Cooperativa de Colombia, sede Bucaramanga.

Correos electrónicos: clarisrg@hotmail.com, yenny.arenas@hotmail.com, erickjohannaguilar29@yahoo. com y yayiro84@hotmail.com, respectivamente.

Recibido: 30 de septiembre del 2013 Aprobado: 7 de octubre del 2013

Cómo citar este artículo: Marien Yolanda Correa-Corredor, Noris Mendoza-Pérez, Clara Milena RincónGuauque, Yenny Marcela Arenas-Rueda, Erick Johann Aguilar-Noriega, José Eliecer Villamizar-Mendoza. El feminicidio: realidad o mentira dentro de la política pública colombiana. DIxI. Diciembre 2013. At. 77.

\section{Resumen}

Este ejercicio académico parte del estado del arte del feminicidio en seis países de América Latina - entre ellos Colombia - durante los dos últimos lustros, para evidenciar la necesidad de proponer la tipificación del feminicidio, no como agravante del homicidio, sino como delito autónomo en la legislación colombiana. Se escribió en la línea de política pública, desde las teorías del feminicidio de Diana Russell y de Marcela Lagarde para proteger a las mujeres víctimas, y fue el resultado de dos trabajos de investigación terminados; se concluye con que buena parte de la política pública se apoya la disminución de la violencia contra mujeres y se modifican los imaginarios.

Palabras clave: feminicidio, misoginia, muerte a mujeres, mujer, violencia de género.

\section{Feminicide: Reality or Myth in Colombian Public Policy}

\begin{abstract}
This academic exercise is based on the state of the art on feminicide in six Latin American countries, including Colombia, over the past two decades to show the need to propose a definition of feminicide, not as an aggravating aspect of homicide but as a separate offense under Colombian law. It was written based on the theory of feminicide of Diana Marcela Russell and Lagard, in line with public policy to protect women victims and was the result of two completed research papers. The conclusion is that a large part of public policy supports a decrease in violence against women and also serves to modify collective concepts.
\end{abstract}

Keywords: feminicide, misogyny, killing women, women, gender violence.

O FEMINICÍDIO: REALIDADE OU MENTIRA DENTRO DA POLÍTICA PÚBLICA COLOMBIANA

\section{Resumo}

Este exercício acadêmico parte do estado da arte do feminicídio em seis países da América Latina - entre eles a Colômbia - durante os dois últimos anos, para evidenciar a necessidade de propor a tipificação do feminicídio, não como agravante do homicídio, mas sim como delito autônomo na legislação colombiana. Escreveu-se na linha de política pública, desde as teorias do feminicídio de Diana Russell e de Marcela Lagarde para proteger as mulheres vítimas, e foi o resultado de dois trabalhos de pesquisa terminados, conclui-se com que boa parte da política pública se apoia na diminuição da violência contra mulheres e modificamse os imaginários.

Palavras-chave: feminicídio, misoginia, morte a mulheres, mulher, violência de gênero. 


\section{INTRODUCCIÓN ${ }^{1}$}

Este artículo de reflexión es el resultado de una investigación terminada, que si bien se conjugó en dos trabajos de grado, significó el esfuerzo conjunto para entender desde un análisis ajeno y propio la caracterización del feminicidio y la necesidad de aportar una propuesta de cambio en la política pública colombiana, dado que la violencia de género sobre las mujeres - problemática ancestral que se ha desarrollado a lo largo de la historia de la humanidad- es un tema de primera plana en los medios de comunicación, tanto por las víctimas y la barbarie que constituye esta clase de conductas, como por la importancia de diseñar una propuesta de norma que tipificara la muerte de la mujer a manos de uno o varios hombres, quienes incurrieron en tal conducta sólo por el hecho de la víctima era mujer. Entonces, se reunieron en este artículo las posturas dentro de ordenamientos jurídicos de algunos países de América Latina y de Colombia, las perspectivas que el tema genera desde su situación en Colombia y aspectos relevantes del proyecto de ley "Mujer con Justicia", como una propuesta de cambio en la legislación colombiana.

En efecto, se encuentra que en algunos países el delito del feminicidio sí está tipificado como figura penal autónoma, cambio legislativo surgido por las situaciones preocupantes en cuanto a los indicadores de comisión de conductas de esta categoría, resultado de la misoginia, pero también, luego de que organizaciones femeninas promovieran luchas pacíficas para hacerle ver a los decisores políticas sobre la necesidad de medidas especiales de protección frente a la vida de las mujeres. En el caso colombiano no hay una norma especial de feminicidio, ya que se ha constituido como una causal de agravación del homicidio el hecho de que la víctima sea mujer y el victimario su pareja o alguien muy relacionado con ella. Sin embargo, de acuerdo con las teorías de Lagarde y de Russell - quienes hablaron de femicidio y luego feminicidio- se buscó evidenciar la gravedad de un problema social al incorporar en el lenguaje una denominación sobre el asesinato de mujeres por hombres, por el hecho de ser estas muertes el resultado del desprecio y la denigración a lo femenino.

1 Este artículo es una reflexión derivada de dos investigaciones terminadas y aprobadas: "Estado del arte: el feminicidio como delito en América Latina durante los años 2002-2012" y "El feminicidio: propuesta jurídica para tipificarlo como delito autónomo en Colombia”, presentadas en enero del 2013
Russell $^{2}$ afirma que las muertes de las mujeres por ser mujeres tienen que ver con un asunto de superioridad de género, quedando oculta y permitiendo que no se logren reducir las violencias ni incrementar las políticas para tratar este fenómeno.

Los egresados autores de este ejercicio académico iniciaron su gusto por el tema dentro de un semillero de investigación emanado de la cátedra Seminario Regional - violencia de género, punto de partida que los llevó a formular un nuevo proyecto de ley "Mujeres con Justicia", previas consideraciones sobre varias posturas de diferentes autores y momentos históricos sobre si se debe o no tipificar la conducta del feminicidio en forma autónoma. Pero, en todo caso, la primordial intención desde lo descriptivo, fue abordar un tema que pareciera nuevo, porque los abogados penalistas, por lo menos en Colombia, no lo manejan con la denominación de feminicido, a pesar de su incidencia social, por lo que exige de los estudiosos del derecho "ir tras las huellas" del feminicidio.

\section{MATERIALES Y METODOLOGÍA}

La investigación con sus dos productos (monografías de grado) fue observacional entre descriptiva y analítica, por cuanto se revisaron y presentaron los aspectos relevantes de las normas imperantes en seis países de América Latina sobre la política criminal frente a la conducta de la muerte de una mujer por el hecho de ser mujer, en el periodo comprendido entre el 2002 y el 2012. Asimismo, se hizo un análisis sobre la realidad colombiana y las consideraciones para hacer una propuesta de cambio en la política pública. La revisión de documentación se hizo con acceso a Internet, textos impresos y también algunos correos electrónicos con respuestas de personas que manejan el tema.

Es una investigación cualitativa con acercamiento a la forma comparativa, dado que se analizaron y sintetizaron diferencias y similitudes de los ordenamientos jurídicos de los países estudiados, y las condiciones socioculturales sobre el tema que dio lugar a la investigación.

2 D. Russell \& J. Radford. Feminicidio. La política del asesinato de las mujeres. http://books.google.com/books?id=AqlyKJQFjLYC\&printsec= frontcover\&source $=\mathrm{gbs}$ ge_summary_r\&cad $=0 \# \mathrm{v}=$ onepage $\& \mathrm{q} \& \mathrm{f}=\mathrm{false}$ (10 febrero del 2011). 


\section{RESULTADOS}

Los resultados se presentarán en dos momentos: el primero relacionado con los imaginarios histórico-juridicos del feminicidio en América Latina durante los años 2002 al 2012, y el segundo sobre la propuesta normativa legislativa para tipificar el delito del feminicidio en Colombia, como figura autónoma con alcance pedagógico hacia la reinserción del hombre violentador.

\section{A. Acerca de los imaginarios sobre el feminicidio en América Latina}

La revisión de los ordenamientos jurídicos de seis países de América Latina arrojó la información que se presenta en los siguientes apartados.

\section{Guatemala-América Central}

Por las relaciones desiguales de poder entre hombres y mujeres en el ámbito social, económico, jurídico, político, cultural y familiar, por una parte, así como el problema de violencia y discriminación en contra de mujeres, niñas y adolescentes imperante en Guatemala, por la otra, agravado con el asesinato y la impunidad constantes, el Congreso de la República de Guatemala promulgó el Decreto 22-2008 - "Ley contra el Femicidio y otras formas de violencia contra la mujer" -, en el que se introduce el delito de femicidio (artículo $6^{\circ}$ ) bajo el siguiente tenor:

Comete el delito de femicidio quien, en el marco de las relaciones desiguales de poder entre hombres y mujeres, diere muerte a una mujer, por su condición de mujer, valiéndose de cualquiera de las siguientes circunstancias:

- Haber pretendido infructuosamente establecer o restablecer una relación de pareja o de intimidad con la víctima.

- Mantener en la época en que se perpetre el hecho, o haber mantenido con la víctima relaciones familiares, conyugales, de convivencia, de intimidad o noviazgo, amistad, compañerismo o relación laboral.

- Como resultado de la reiterada manifestación de violencia en contra de la víctima.

- Como resultado de ritos grupales usando o no armas de cualquier tipo.

- En menosprecio del cuerpo de la víctima para satisfacción de instintos sexuales o cometiendo ac- tos de mutilación genital o cualquier otro tipo de mutilación.

- Por misoginia.

- Cuando el hecho se cometa en presencia de las hijas o hijos de la víctima.

- Concurriendo cualquiera de las circunstancias de calificación contempladas en el art. 132 del Código Penal.

La persona responsable de este delito será sancionada con pena de prisión de veinticinco a cincuenta años, y no podrá concedérsele la reducción de la pena por ningún motivo. Las personas procesadas por la comisión de este delito no podrán gozar de ninguna medida sustitutiva. $^{3}$

Se puede afirmar que dicho Decreto fue el resultado de la responsabilidad estatal frente a su compromiso de aplicar las convenciones internacionales a las cuales se adhirió: 1) Convención sobre la eliminación de todas las formas de discriminación contra la mujer, adoptada por Decreto-ley No. 49-82, y 2) Convención Interamericana para prevenir, sancionar y erradicar la violencia contra la mujer, aprobada por Decreto 69-94. En todo caso influyeron de los movimientos feministas para buscar la erradicación de la violencia contra las mujeres.

La norma se sustentó en estadísticas impactantes, dentro de las cuales se muestran algunas como soporte. El Instituto Nacional de Estadísticas (INE) evidenció que entre el 2002 y el 2003 la PNC reportó ascenso en un $42,5 \%$ de las muertes de mujeres a manos de sus parejas. Del 2003 al 2004 el aumento fue del 73\%. El incremento del feminicidio en cuatro años fue de $112,25 \%$ (gráfico 1), siendo el arma de fuego el instrumento más utilizado para esta clase de conductas.

El perfil de las víctimas fue importante en Guatemala porque ayudó a determinar los escenarios en los que estas se movían y con quiénes se relacionaban, a fin de evitar la comisión de los hechos, que en la época de las estadísticas mostradas se llamaba homicidio. Impera el número de víctimas que son amas de casa. ${ }^{4}$

\section{México-Centroamérica}

La Ley General de Acceso de las Mujeres a una Vida Libre de Violencia (LGAMvlv) publicada en el Diario

\footnotetext{
3 Guatemala, Decreto 22-2008.

4 Recuérdese que sólo hasta el 2008 se emitió la ley que tipificó la
} conducta del feminicidio. 


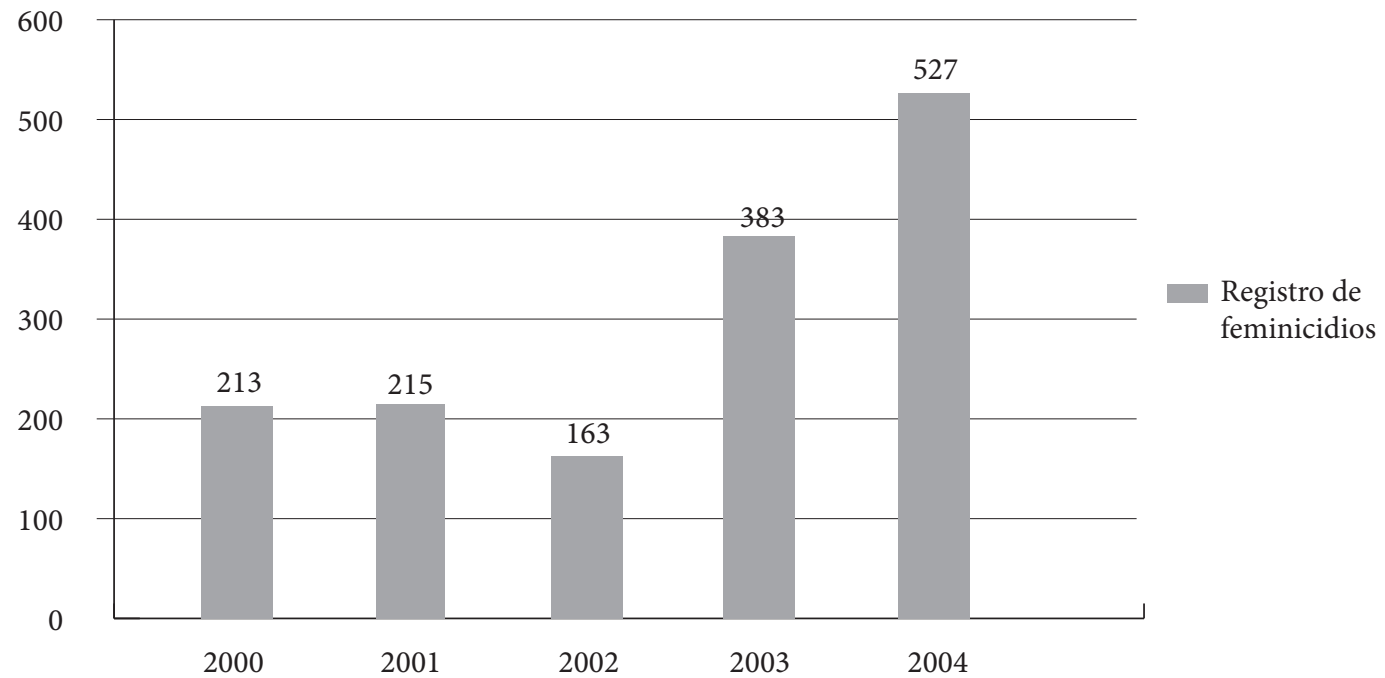

Gráfico 1. Estadística de asesinatos contra mujeres en Guatemala (2000-2004)

Fuente. Instituto Nacional de Estadísticas (INE) Guatemala, 2005

Oficial el $1^{\circ}$ de febrero del 2007 y reformada en el 2009 y el 2012, cuyo objeto fue determinar una actividad coordinada en los Estados Unidos Mexicanos frente a la prevención, sanción y erradicación de la violencia contra las mujeres, busca garantizarles una vida digna en condiciones de igualdad desde una perspectiva de género, y definir las distintas tipologías de violencia contra una fémina. En el Capítulo VI, artículo 21, inciso $1^{\circ}$, se definió el concepto de violencia feminicida, así:

Es la forma extrema de violencia de género contra las mujeres, producto de la violación de sus derechos humanos, en los ámbitos público y privado, conformada por el conjunto de conductas misóginas que pueden conllevar impunidad social y del Estado y puede culminar en homicidio y otras formas de muerte violenta de mujeres.

El artículo 22 de la LGAMVLV creó la alerta de violencia de género para establecer gestiones que eliminen la violencia contra la mujer. A su vez, el artículo 26 exige que el Estado mexicano subsane el daño causado por la violencia feminicida, bajo la mirada internacional de los derechos humanos y dentro de tres parámetros: el derecho a la justicia, el derecho a la rehabilitación y el derecho a la satisfacción. Ello porque la intención no es sólo la sanción penal sino el apoyo físico y psicológico a las víctimas, para lograr rehabilitación integral y prevención. En el título III de esta ley se creó el sistema nacional para prevenir, atender, sancionar y erradicar la violencia contra las mujeres, mediante acciones in- terinstitucionales en las que se dio campo amplio a la investigación. ${ }^{5}$

Un aspecto para resaltar en el caso mexicano es que el concepto de feminicidio agrupa a la mujer víctima y su agresor, y al Estado donde ocurrió el hecho, por la presunta omisión o negligencia de sus agentes. ${ }^{6}$ Ciudad Juárez, por ejemplo, es un escenario con alto índice de asesinato de mujeres, ${ }^{7}$ circunstancia esta que ha hecho que activistas y organizaciones reacciones frente a " $[\ldots]$ brutales asesinatos de mujeres, casi siempre jóvenes, pertenecientes a la clase trabajadora e inmigradas a la ciudad".

5 Uno de los trabajos investigativos más consultados ha sido el titulado "México: evolución de las tasas nacionales de defunciones femeninas con presunción de homicidio, según el año de ocurrencia, 1985-2009”, cuyas fuentes primarias fueron los datos estadísticos de doce procuradurías generales de justicia. Se presume, entonces, que este cambio de estadísticas surge porque en el 2007 se profirió la ley contra la violencia de la mujer. El estudio mostró el problema en Ciudad Juárez o en Chihuahua, Baja California, Durango, Sinaloa, Sonora, Tamaulipas, Nayarit, México, Oaxaca, Michoacán, entre otras regiones, sin desconocer la situación en otros estados.

6 Así lo recalcó la Corte Internacional en el caso de Campo Algodonero, ante las irregularidades de las autoridades mexicanas tanto en la investigación como en la judicialización de las conductas.

7 Si en 1993 se asesinaba a una mujer cada doce días en Ciudad Juárez, en el 2010 se cometía este mismo delito sobre una mujer cada 20 horas. Cfr. E. Bräth. Feminicidios en México. Organizaciones de derechos de las mujeres y derechos humanos luchan contra la "cultura del silencio". http://www. boell-latinoamerica.org/web/103-Feminicidios_en_M\%C3\%A9xico-1164. html (11 enero, 2013).

8 E. Bräth. Feminicidios en México. Organizaciones de derechos de las mujeres y derechos humanos luchan contra la "cultura del silencio". http://www.boell-latinoamerica.org/downloads/hbs-Feminicidios_ 

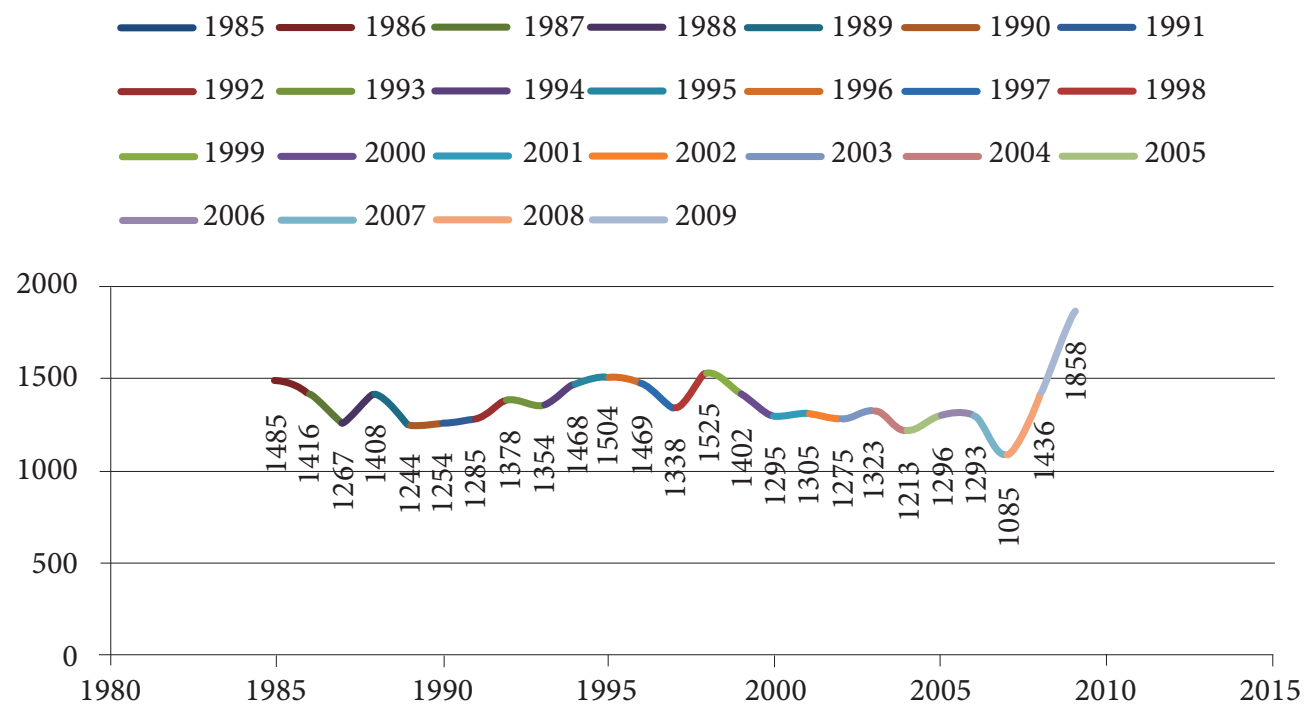

Gráfico 2. Acumulado de defunciones femeninas con presunción de homicidio en México 1985-2009 Fuente. Naciones Unidas, et.al., 2011

Precisamente, hay procesos judiciales que se hicieron públicos ante el mundo, por su trámite ante la Corte Interamericana de Derechos Humanos, como los de Rosendo Cantú, mujer indígena Me' phaa, o el de Laura Berenice Ramos Monárrez, de 17 años de edad y estudiante del quinto semestre de preparatoria. En esos dos adelantados contra México se falló con la determinación de que el Estado había violado los derechos a la vida, integridad personal y libertad personal reconocidos en los artículos 4.1, 5.1, 5.2 y 7.1 de la Convención Americana, en relación con la obligación general de garantía contemplada en el artículo 1.1 y la obligación de adoptar disposiciones de derecho interno contemplada en el artículo 2 de esta, así como con las obligaciones contempladas en el artículo 7.b y 7.c de la Convención Belém do Pará. No son las únicas experiencias en que se determinó responsabilidad estatal.

Entre 1985 y el 2009 el acumulado de defunciones femeninas con presunción de homicidio en México fue de 34.176 víctimas. El gráfico 2 muestra las estadísticas de interés en el caso mexicano.

\section{Costa Rica-Centroamérica}

En Costa Rica se tipificó el feminicidio mediante la Ley 8.589 de penalización de la violencia contra las mujeres, proferida el 25 de abril del 2007. Su artículo

MC.pdf (15 septiembre, 2012).
21 describe así el tipo penal: "Artículo 21. Femicidio. Se le impondrá pena de prisión de veinte a treinta y cinco años a quien dé muerte a una mujer con la que mantenga una relación de matrimonio, en unión de hecho declarada o no". Es una ley que persigue garantizar y proteger los derechos de las mujeres víctimas de violencia física, psicológica, sexual o patrimonial, en razón a su discriminación por género. Sin embargo, el artículo que tipificó la conducta del feminicidio se considera no compatible con el artículo 4.1 de la Convención Americana de los Derechos Humanos, dado que, según Rojas \& Herrera, ${ }^{9}$ protege

[...] sólo la vida de las mujeres mayores de edad, casadas o que viven en una unión de hecho o posean las aptitudes para estarlo, dejando desprotegidos al resto de los seres humanos. Dicho artículo le da más importancia a la vida de este sector determinado de la sociedad, por encima de los demás seres humanos, cosa que no va de acuerdo con el art. 4.1 de la CADH. Por esta razón se considera que este artículo de la Ley no debería seguir vigente tal y como está redactado en este momento.

La ley en comento fue resultado de una propuesta del poder ejecutivo de Costa Rica, desde donde se justi-

9 C. Rojas \& K. Herrera. (2009). Análisis sobre la eficacia de los tipos penales especiales que introduce la Ley de Penalización de la violencia contra las mujeres, enfocado a los delitos contra la integridad física de las personas y su constitucionalidad. p. 213. Costa Rica: Universidad de Costa Rica, Facultad de Derecho. www.iij.ucr.ac.cr/download/file/ fid/305-. (23 septiembre, 2012). 


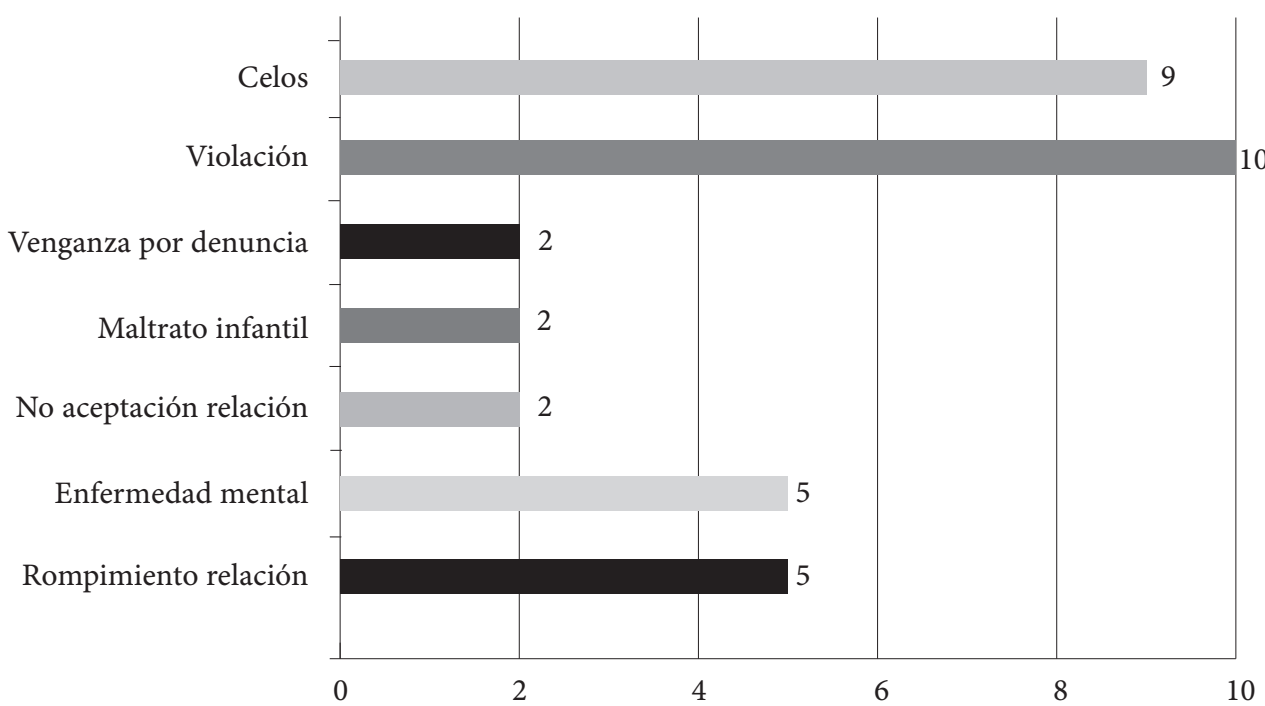

Gráfico 3. Distribución del detonante en casos de feminicidio en Costa Rica, 2011

Fuente. González Morales, 2012

ficó la necesidad de responder a las exigencias en el orden internacional, mediante medidas que eliminaran la histórica discriminación contra la mujer, y en especial la prevención de violencias que la siguieran victimizando. Luego, como lo expresara en el 2004 la Sala Constitucional de la Corte Suprema de Justicia costarricense "la sociedad costarricense no está dispuesta a tolerar este tipo de conductas [la violencia mediante asesinatos de mujeres]" ${ }^{10}$

Los decisores políticos tuvieron en cuenta las siguientes estadísticas: 28 mujeres asesinadas por condición de género; 12 mujeres agredidas presuntamente por su pareja, de los cuales el $90 \%$ involucró al concubino de la víctima; $75 \%$ de las víctimas se dedicaban a labores del hogar; el instrumento de mayor utilización para eliminar la vida de las mujeres fueron las armas de fuego. ${ }^{11}$ Asimismo, se detectaron 62 casos de mujeres asesinadas en el 2011. De este dato, el 64,5\% fueron casos de feminicidio amparados en los dos ámbitos de aplicación que se han relatado, equivalente a 40 féminas. El restante 35,5\% correspondió a homicidios dolosos perpetrados por móviles o razones diferentes. De las 40 mujeres asesinadas, 12 de ellas se circunscriben al artículo 21 de la Ley de Penalización de la Violencia

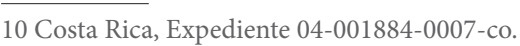

11 M. González. Mujeres fallecidas por femicidio en Costa Rica, bajo el ámbito de la ley de penalización de la violencia contra las mujeres y la aplicación de la Convención Internacional Belém do Pará y CEDAw durante el 2011. www.poder-judicial.go.cr/planificacion/Informes.../164PLA-2012.rtf. (11 septiembre, 2012).
Contra las Mujeres. También se encontró que los celos y la venganza por interposición de denuncia judicial fueron detonantes para la comisión del delito (el $53,8 \%$ de los casos). No obstante lo anterior, en el 2011 sólo hubo un fallo condenatorio.

Por otra parte, como se encontró en González Morales, ${ }^{12}$ se deduce que en Costa Rica el detonante en los femicidios gira alrededor de ataques sexuales, celos, enfermedades mentales y rompimiento de relaciones (gráfico 3).

Como corolario se resalta que en Costa Rica, a pesar de existir el tipo penal de feminicidio, no hay medidas de seguridad efectivas para erradicar la violencia contra la mujer en todos los escenarios, atendiendo al significado de que a este problema le da la Convención Internacional Belém Do Pará. ${ }^{13}$ Eso sí, la legislación costarricense habla de "feminicidio ampliado", cuando se comete: con ataque sexual o con comportamientos psicóticos. No obstante, se encuentra que casos así o por hechos originados en asuntos de celotipia o venganza, a veces los identifican como delitos pasionales.

\section{2 Ídem.}

13 En este instrumento se define la violencia contra la mujer como aquellas actuaciones que afectan física, sexual y psicológicamente a las féminas, teniendo lugar en los hogares o en contextos en los que existan relaciones interpersonales "ya sea que el agresor comparta o haya compartido el mismo domicilio que la mujer”, tipificándose como violaciones, maltratos, trata de personas, prostitución forzada, entre otros hechos complejos. 


\section{Chile-América del Sur}

En Chile se promulgó la Ley No. 20.480 del 18 de diciembre del $2010^{14}$ mediante la cual se modificó el Código Penal y la Ley No. 20.066 del $2005^{15}$ sobre violencia intrafamiliar. En esta nueva Ley se tipificó el delito del Femicidio con aumento de penas. Además se reformaron las normas sobre parricidio. El artículo $1^{\circ}$ de la ley en comento, numerales $6^{\circ}$ y $7^{\circ}$, introdujo modificaciones a los artículos 390 y 489 del Código Penal, así:

6) En el artículo 390:

a) Reemplázase la expresión "a su cónyuge o conviviente" por la siguiente: "a quien es o ha sido su cónyuge o su conviviente".

b) Incorpórase el siguiente inciso segundo:

"Si la víctima del delito descrito en el inciso precedente es o ha sido la cónyuge o la conviviente de su autor, el delito tendrá el nombre de femicidio".16

7) Intercálase, en el inciso segundo del artículo 489, a continuación de la palabra "delito", la siguiente frase: "ni tampoco entre cónyuges cuando se trate de los delitos de daños indicados en el párrafo anterior".

La Ley No. 20.480 del 2010, resultado de los altos índices de violencia contra la mujer en el hogar y complemento a la Ley No. 20.066 sobre violencia intrafamiliar, es insuficiente porque no hay diferencia en las penas que se imponen cuando la víctima es una mujer o un hombre. ${ }^{17}$ Pero de todas formas, la norma constituyó un avance frente a un desconocimiento del asunto en época pretérita; porque, incluso, esta Ley realizó modificaciones integrales de importancia; por ejemplo, desapareció la diferencia que existía en materia de eximente de responsabilidad sólo para el hombre que matase a su mujer por adulterio, dado que la exoneración quedó sin discriminación de género y cuando se

14 Chile. Biblioteca del Congreso Nacional. Ley No. 20.480 (2010, diciembre 14). Por medio de la cual se modifica el Código Penal y la Ley No. 20.066 sobre violencia intrafamiliar, estableciendo el "Femicidio" aumentando las penas aplicables a este delito y reforma las normas sobre parricidio. http://www.leychile.cl/Navegar?idNorma=1021343 (22 septiembre, 2012)

15 Chile. Biblioteca del Congreso Nacional. Ley No. 20.066 (2005, septiembre 21). Establece ley de violencia intrafamiliar. http://www.leychile. $\mathrm{cl} /$ Navegar?idNorma=242648 (22 septiembre, 2012).

16 Chile. Biblioteca del Congreso Nacional. Ley No. 20.480. cit.

17 Es decir, el sujeto activo pareja de la mujer víctima, no tiene una pena diferencial cuando se trata de sujeto activo mujer que le quita la vida a su pareja hombre. obraba para "evitar un mal grave para su persona o derecho o los de un tercero".

Los cambios de la Ley No. 20.480 del 2010 en el delito de parricidio mostraron ampliación de sujetos activos (también a las ex parejas), diferenciando: si son los varones quienes asesinan a sus mujeres (convivientes o ex parejas) será un caso de femicidio; pero si las víctimas son los hombres se trata de parricidio. Claro está, que la Ley muestra una connotación especial frente al "homicidio de mujeres por quienes son o han sido sus compañeros", con dos agravantes: "el contexto intrafamiliar y la condición de mujer". Debe entonces resaltarse, que el legislador chileno consideró que el estado de indefensión de las víctimas en relación parental con sus victimarios, por razones de conocimiento, confianza o cariño, las hace más vulnerables.

Por ello, la víctima está en una posición de mayor debilidad, con menos posibilidades de repeler la ofensa, lo que denota la particular gravedad de la conducta. No es lo mismo un ex conviviente con el que no se tuvo hijos ni se mantuvo contacto por años, que otro con el que sí se da una o ambas circunstancias. ${ }^{18}$

Los decisores políticos en Chile también tuvieron en cuenta estadísticas sobre casos de feminicidio, presentados como crímenes pasionales para justificar la agresión contra las mujeres por parte de los hombres. Sin embargo, en el 2004 iniciaron la campaña "Por la vida de las mujeres: Ni una muerte +" en cabeza de la Red Chilena contra la Violencia Domestica y Sexual. ${ }^{19}$ Precisamente, dentro de los crímenes contra mujeres en el periodo 2001-2002, se tuvieron 28 feminicidios y 29 no feminicidios en el área metropolitana de Santiago de Chile; priorización de los casos de feminicidios íntimos divulgados por medios de comunicación; el domicilio común entre pareja y víctima fue el lugar de mayor ocurrencia de los hechos de feminicidio (55\% del total de casos).

Se muestra que la mayor cantidad de feminicidios en Chile durante el 2011 sucedieron en el domicilio común; en un segundo nivel fueron en el de la víctima. En todo caso, fueron hechos causados por personas con las cuales la víctima mantenía una relación estre-

18 M. Santibáñez \& T. Vargas (2011). Reflexiones en torno a las modificaciones para sancionar el femicidio y otras reformas relacionadas (Ley No. 20.480). Revista Chilena de Derechos vol. 38 núm. 1. Santiago. http://www.scielo.cl/pdf/rchilder/v38n1/art13.pdf. (30 octubre, 2012).

19 Organización de las Naciones Unidas. Femicidio en Chile. http://www. onu.cl/pdfs/fenicidio.pdf (23 septiembre, 2012). 


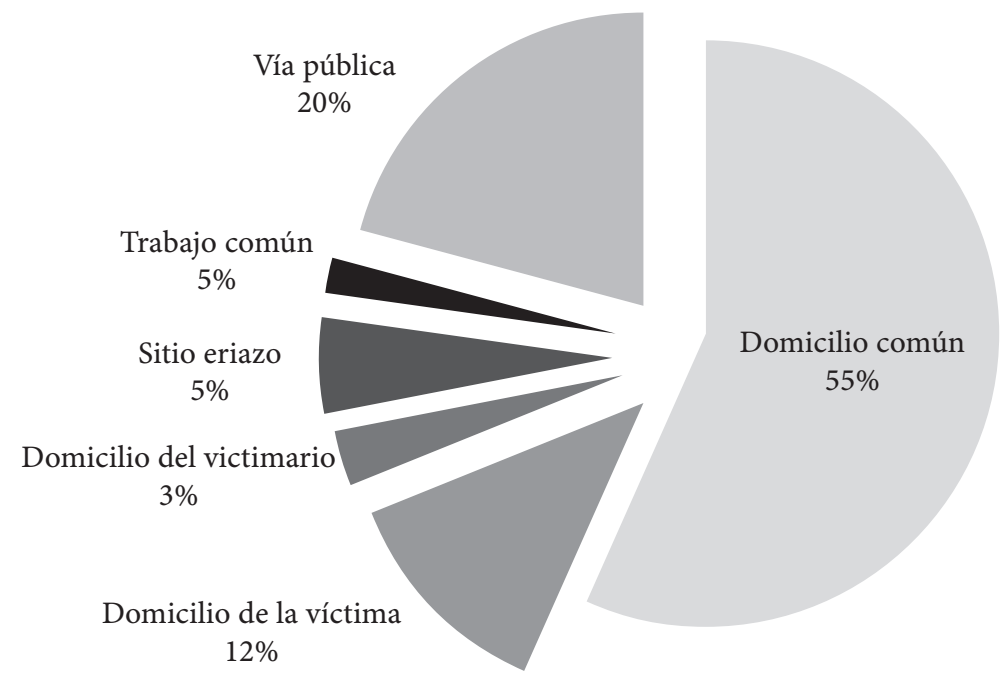

Gráfico 4. Lugar de ocurrencia del feminicidio

Fuente. Circuito Nacional de Femicidio, 2011 ${ }^{20}$

cha, casos que siguen considerándose violación de los derechos fundamentales y derechos humanos.

Según los registros, en el 2011, en el 32,5\% de los casos la relación era de convivientes; asimismo, el $32,5 \%$ de los casos la relación era de ex convivientes; el $25 \%$ de los casos correspondieron a relación de cónyuges, y el 10\% de los casos se trataba de una relación en la que no convivían, lo que muestra claramente el hecho de que en la gran mayoría de los casos, el feminicidio se da a partir de una relación entre dos personas entre las cuales surge una diferencia en la que el género prevalece por medio de manifestaciones de violencia. ${ }^{21}$

Curiosamente, y de manera similar al de otros países consultados, en Chile los casos de feminicidio también aumentan las estadísticas de homicidios con estigmatización de ser casos de crímenes pasionales. Sin embargo, se debe resaltar que se avanzó en una nueva caracterización del delito, al punto en que se encontraron estadísticas del llamado Circuito Nacional de Femicidio, conformado los por Carabineros de Chile, el Servicio Nacional de la Mujer (Sernam) ${ }^{22}$, el Servicio Nacional de Menores (Sename), y el Ministerio del Interior y Seguridad Pública, que muestran

20 Circuito Nacional de Femicidio. Op. cit.

21 Circuito Nacional de Femicidio. Red de asistencia a víctimas. Informe anual año 2011, Protocolo intersectorial de atención a víctimas de feminicidio. http://www.apoyovictimas.cl/wp-content/uploads/2012/04/ Informe-Cicuito-de-Femicidio-a\%C3\%B1o-2011.pdf (21 julio, 2012).

22 Chile. Servicio Nacional de la Mujer. http://portal.sernam. $\mathrm{cl} /$ ?m=programa\&i=15-Servicio Nacional de la mujer -gobierno de chile - feminicidio - 2008 (22 septiembre, 2012). datos de comisión de tales conductas por regiones y por lugares de ocurrencia del crimen, entre otros. Sólo como ejemplo se presenta el gráfico 4 , que incluye algunos datos encontrados sobre sitio de comisión de la conducta penal, que, similar a otros países, se trata de crímenes cometidos mayormente en el domicilio común. En todo caso, fueron hechos causados por personas con las cuales la víctima mantenía una estrecha relación, y que siguen considerándose violación de los derechos fundamentales y de los derechos humanos.

\section{Perú-América del Sur}

En Perú se promulgó la Ley 29.819 del 27 de diciembre del 2011 en la que se incorporó el delito de feminicidio en el Código Penal Peruano. Su artículo 107 dice textualmente:

Artículo 107. Parricidio/Feminicidio: El que, a sabiendas, mata a su ascendiente, descendiente, natural o adoptivo, o a quien es o ha sido su cónyuge, su conviviente, o con quien esté sosteniendo o haya sostenido una relación análoga será reprimido con pena privativa de libertad no menor de quince años.

La pena privativa de libertad será no menor de veinticinco años, cuando concurran cualquiera de las circunstancias agravantes previstas en los numerales 1,2, 3 y 4 del artículo 108 .

Si la víctima del delito descrito es o ha sido la cónyuge o la conviviente del autor, o estuvo ligada a él por 
una relación análoga, el delito tendrá el nombre de Feminicidio.

Fue evidente la intención de la Ley 28.819 de incorporar el delito de feminicidio, dado que tiene artículo único que modificó y amplió la disposición contenida en el Código Penal sobre parricidio. Este es un avance legislativo no exento de discrepancias y posturas opuestas a partir de los diferentes proyectos de ley que se propusieron antes del que definitivamente se convirtió en norma. Algunos juristas peruanos denominaron esta nueva lectura en el derecho penal como "la sexualización del Código Penal", ${ }^{23}$ considerando positiva la reivindicación de un tipo penal diferente a la violencia intrafamiliar, pero censurándolo tal cual quedó en la disposición legal penal al considerar que no describió la naturaleza misma del feminicidio, como se ha venido presentando por Diana Russell. Bringas ${ }^{24}$ dice que, aun dado

[...] [el] esfuerzo del legislador, no se ha observado escrupulosamente el principio de legalidad penal con esta tipificación, pues no se han precisado los elementos normativos de un tipo penal de estructuración eminentemente subjetiva (la agravación de la pena no se explica a partir de la verificación del resultado, ontológicamente considerado, sino a partir de la determinación subjetiva del autor para ocasionar el resultado muerte). Promulgada la ley, corresponde ahora al desarrollo casuístico y teórico suplir esta deficiencia, sin apartarse de las garantías de mínima intervención y última ratio del derecho penal.

La cuestión es que en Perú, aun existiendo la ley comentada, no es culturalmente aceptada la condición de defensa de los derechos de la mujer por las costumbres machistas de tal sociedad. Incluso, desde la reflexión académica, algunos opositores a la Ley 28.819 del 2011 la consideran inconstitucional por violar los principios fundamentales de la no discriminación y la igualdad, al no dar tratamiento similar a hombres y mujeres. En todo caso, a pesar de las críticas de la autora comentada, se observa que la Ley permitió tener una lectura diferente en cuanto a la objetivización de las mujeres por parte de algunos hombres, para quienes impera su poder y victimizan a la mujer por cuestión de género.

23 S. Bringas. Feminicidio inecesidad de sexualizar el derecho penal? A propósito de la Ley No. 29.819. pág. 3. http://www.derechoycambiosocial. com/revista028/Feminicidio.pdf (22 septiembre, 2012).

24 Ídem.
La información recabada va desde febrero del 2003 hasta marzo del 2004. Todos los datos recogidos permiten una primera aproximación a la realidad, así como la posibilidad de evidenciar que el "feminicidio" no es una realidad ajena al país. Durante este periodo se han registrado 297 casos de violencia extrema contra la mujer, de los cuales más del 56\% han culminado con la muerte de la agredida. ${ }^{25}$

Las estadísticas de muerte de mujeres en el Perú en el periodo enero 2004-julio 2007 muestran 403 víctimas, con una reducción importante en el 2005 (de 130 a 92 mujeres) y un aumento en similar proporción en el 2006 (de 92 a 143). Las edades en el 55\% de los casos oscilaron entre 16 y 35 años de edad, lo cual significa que las personas jóvenes tienen mayor riesgo de ser víctimas. Bringas ${ }^{26}$ mencionó que en el periodo enero a noviembre del 2011 hubo 73 casos de mujeres asesinadas por sus parejas; en el 2010 se conocieron 168 casos (121 muertes y 47 tentativas), y en el 2009 se radicaron 203 casos (139 muertes y 64 tentativas). En las anteriores estadísticas imperó la causal de celos o por negativa a mantener alguna relación sentimental. Por su parte, el periódico El Comercio publicó que durante el 2011 hubo 93 feminicidios y 66 tentativas. En el 2012, a septiembre, se registraron 54 feminicidios y 65 tentativas. ${ }^{27}$ Una situación compleja que dio lugar a la propuesta de modificación del Código Penal Peruano, en el sentido de incrementar las penas por feminicidio - incluso hasta la cadena perpetua -, idea que se archivó por la consideración de que no deben hacerse diferenciaciones de género entre hombres y mujeres.

\section{Colombia-América del Sur}

En este país actualmente no se encuentra tipificado el delito de feminicidio, aun cuando la muerte de mujeres por su condición de tal exista como un hecho frecuente. Entonces, estos casos son tratados como homicidio agravado o violencia intrafamiliar. Precisamente, un ejemplo de feminicidio fue el de Rosa Elvira Cely, quien fue torturada, empalada y luego asesinada en Bogotá a finales de mayo del 2012. A partir este hecho,

25 Centro de la Mujer Peruana Flora Tristán. Reporte feminicido en el Perú. http://www.flora.org.pe/investigaciones/feminicidio.pdf (23 septiembre, 2012).

26 S. Bringas. Op. cit.

27 El Comercio. Pe. (2012, septiembre 26). Delito de feminicidio será castigado hasta con cadena perpetua en el país. http://elcomercio.pe/ actualidad/1475123/noticia-delito-feminicidio-castigado-hasta-cadenaperpetua-pais (30 septiembre, 2012). 
la senadora Gloria Inés Ramírez Ríos radicó el proyecto de Ley "Rosa Elvira Cely" No. 49 del 2012 - Senado. ${ }^{28}$ "Por la cual se crea el tipo penal feminicidio como delito autónomo y se dictan otras disposiciones", con tres aspectos importantes: 1) tipificar el feminicidio como un delito autónomo; 2) garantizar la debida diligencia, idoneidad y oportunidad en la investigación y sancionar la violencia contra las mujeres por el hecho de ser mujeres; y 3 ) adoptar estrategias de sensibilización de la sociedad colombiana en la prevención de la violencia feminicida.

En Colombia existe la Ley 248 de $1995^{29}$ que ratificó la Convención Internacional para prevenir, sancionar y erradicar la violencia contra la mujer. También está la Ley 294 del 16 de julio de 1996, ${ }^{30}$ que desarrolla el artículo 42 de la Constitución Política de Colombia, norma que contempla que la familia es el núcleo central de la sociedad, con una protección especial y una prevención y sanción en casos de violencia intrafamiliar. La ley nacional fue modificada por la $575 \mathrm{del} 2000$ y luego por la Ley 1257 del $2008,{ }^{31}$ con incorporación de medidas de protección en casos de violencia intrafamiliar fuera y dentro del entorno familiar. ${ }^{32}$ Por su par-

28 Consultar el proyecto en G. I. Ramírez. Proyecto de ley "Rosa Elvira Cely” No. 49 del 2012-Senado. Villamil Martínez Cristina (2012, agosto 24). Atención ciudadana Congreso. Re: PL: 49/2012 S. https://exchange. camaradirecta.com/owa/?ae=Item \&t=IPM.Note\&id=RgAAAAAU1llV X9B5QJJqYVFVk1C5BwAFKQnbTl0aQYV8pT0F4ZYfAAAStAq6AAA FKQnbTl0aQYV8pT0F4ZYfAAASuQ\%2frAAAJ (24 agosto, 2012).

29 Esta ley fue consultada en: Colombia. Congreso de la República. Ley 248 (1995, diciembre 29). Por medio de la cual se aprueba la Convención Internacional para prevenir, sancionar y erradicar la violencia contra la mujer. http://www.elabedul.net/Documentos/Leyes/1995/Ley_248.pdf(23 septiembre, 2012).

30 Esta ley fue consultada en: Colombia. Congreso de la República. Ley 294 (1996, julio 16). Por la cual se desarrolla el artículo 42 de la Constitución Política y se dictan normas para prevenir, remediar y sancionar la violencia intrafamiliar. http://www.secretariasenado.gov.co/senado/ basedoc/ley/1996/ley_0294_1996.html (23 septiembre, 2012).

31 Esta Ley fue consultada en: Colombia. Congreso de Colombia. Ley 1257 (2008, diciembre 4). Por la cual se dictan normas de sensibilización, prevención y sanción de formas de violencia y discriminación contra las mujeres, se reforman los Códigos Penal, de Procedimiento Penal, la ley 294 de 1996 y se dictan otras disposiciones. http://www.secretariasenado.gov.co/senado/basedoc/ley/2008/ley_1257_2008.html. (23 septiembre, 2012).

32 La Ley 1257 del 2008, en su artículo $2^{\circ}$, define la violencia contra la mujer como "cualquier acción u omisión, que le cause muerte, daño o sufrimiento físico, sexual, psicológico, económico o patrimonial por su condición de mujer". Disposiciones que pretendieron garantizar a las mujeres una vida libre de violencia y el reconocimiento de una serie de derechos. Esta Ley incluyó dos importancias circunstancias de agravación del homicidio, siendo la última una aproximación legislativa a la figura del feminicidio; eso sí, sin darle tal denominación. te, el Código Penal Colombiano, o Ley 599 del 2000,33 incluyó la causal de agravación del delito de homicidio, por reforma aplicada desde la Ley 1257 del 2008, la conducta cometida "en los cónyuges o compañeros permanentes [...]", así como "Si se cometiere contra la mujer por el hecho de ser mujer". Asimismo, el Código de Procedimiento Penal o Ley 906 del $2004^{34}$ ha tenido diferentes situaciones respecto a la violencia intrafamiliar. Inicialmente fue querellable, luego se convirtió en conducta oficiosa; con la Ley 1453 del 2011 recuperó la desistibilidad, pero bajo la Ley 1542 del 5 de julio del 2012, que reformó el art. 74, excluye la condición de querellable a esta clase de violencia; afirmación esta última al tenor del texto de su parágrafo:

Parágrafo: En todos los casos en que se tenga conocimiento de la comisión de conductas relacionadas con presuntos delitos de violencia contra la mujer, las autoridades judiciales investigarán de oficio, en cumplimiento de la obligación de actuar con la debida diligencia para prevenir, investigar y sancionar la violencia contra las mujeres consagrada en el artículo $7^{\circ}$ literal b) de la Convención de Belém do Pará, ratificada por el Estado colombiano mediante la Ley 248 de 1995.

En efecto, la violencia contra la mujer o violencia de género fue un hecho considerado por muchos años asunto de la vida privada de las personas, que poco a poco salió a la luz pública para incidir en la transformación de los sistemas jurídicos; no con la agilidad que los grupos defensores de los derechos de la mujer desearían, pero sí intentando una transformación necesaria. V. gr., la Constitución Política de Colombia elevó a rango de derecho fundamental la no discriminación de la mujer frente al hombre. Su artículo 43 dice:

La mujer y el hombre tienen iguales derechos y oportunidades. La mujer no podrá ser sometida a ninguna clase de discriminación. Durante el embarazo y después del parto gozará de especial asistencia y protección del Estado, y recibirá de este subsidio alimentario si entonces estuviere desempleada o desamparada.

33 Consultar la norma en: Colombia. Congreso de la República. Ley 599 Código Penal (2000, julio 24). http://www.secretariasenado.gov.co/senado/basedoc/ley/2000/ley_0599_2000.html. (23 septiembre, 2012).

34 Consultar la norma en: Colombia. Congreso de la República. Ley 906 (2004, agosto 31). Por la cual se expide el código de procedimiento penal. http://www.secretariasenado.gov.co/senado/basedoc/ley/1996/ ley_09060_204a..html. (23 septiembre, 2012). 
El Estado apoyará de manera especial a la mujer cabeza de familia.

La Ley 1257 del 2008 fue reglamentada por: 1) Decreto 4796 del 2011, en el que se contempló la obligación de establecer tanto un plan de salud para ayudar a mujeres víctimas de la violencia, como un subsidio para sustentarles habitación, alimentación y tratamiento psicológico de ellas y sus hijos. 2) Decreto 4463 del 2011, sobre el reconocimiento laboral de las mujeres que evite su discriminación en el trabajo, así como el impulso de empleos no tradicionales a su favor y la garantía de igualdad salarial y sanción de acoso sexual, entre otras medidas. 3) Decreto 4798 del 2011, para garantizar planes educativos sobre el tema objeto de la Ley, capacitar a las víctimas y darles atención preferencial en estudios técnicos o superiores. También está el Decreto 4799 del 2011, cuyo objeto fue reglamentar las Leyes 294 de 1996, 575 del 2000 y la misma 1257 del 2008, en relación con las competencias de las Comisarías de Familia, la Fiscalía General de la Nación, los Juzgados Civiles y los Jueces de Control de Garantías, de manera que se garantice el efectivo acceso de las mujeres a los mecanismos y recursos para su amparo, como instrumentos que erradiquen todas las formas de violencia.

En la jurisprudencia de la Corte Suprema de Justicia en Colombia ${ }^{35}$ no se halla un enfoque a los derechos de las mujeres que evidencie el verdadero significado del feminicidio, aun cuando hay cifras de "mujeres asesinadas por hombres, por causas relacionadas con el poder de género ejercido por el victimario sobre la víctima, traducido en dominación, desprecio, odio e incluso miedo hacia ellas", mediante lo que se podría considerar el errado "sentido de propiedad total de la mujer por el hombre: de su cuerpo, su espíritu y su vida, ${ }^{36}$ una conducta que suele ir acompañada de otras acciones violentas. ${ }^{37}$

35 Se consultaron las sentencias cuyos radicados son: Colombia. Corte Suprema de Justicia. Proceso No. 27839 (2008, diciembre 2). http:// www.usergioarboleda.edu.co/derecho_penal/jurisprudencia_cuarto_ trimestre_2008.htm. (22 septiembre, 2012) y Colombia. Corte Suprema de Justicia. Proceso No. 38607 (2012, mayo 5). www.dmsjuridica.com/.../ SALA.../2012/mayo/38607(02-05-12).doc. (22 septiembre, 2012).

36 B. Pedroza. Discriminación, violencia de género y crisis económica en América Latina. Crisis económica: una perspectiva feminista desde América Latina, págs. 179-202. Instituto de Investigaciones Económicas, Universidad Nacional Autónoma de México, Centro de Estudios de la Mujer (CEM) de la Universidad Central de Colombia y Consejo Latinoamericano de Ciencias Sociales. (2010).

37 Antes de matar a la mujer, el hombre puede haber incurrido en con ductas tales como el hurto, el secuestro, la violación sexual, la tortura, otras conductas aberrantes.
Se puede afirmar que en Colombia sus dirigentes han estado atentos al tema. Por ejemplo, el presidente Juan Manuel Santos incluyó el tema de equidad para las mujeres, fundamentándolo en tres ejes principales: 1) poder para las mujeres; 2) su condición de ser las mejores ejecutoras del presupuesto familiar y social; $y$ 3) manejo de la violencia de género con leyes eficaces y programas que las protejan del abuso. Augusto Posada Sánchez, presidente de la Cámara de Representantes de Colombia, presentó en el 2012 el proyecto de ley "No. 003 del 2012, por medio del cual se crea la Unidad de vigilancia contra el maltrato a la mujer", para vigilar el cumplimiento y la aplicación de las normas sobre el tema, con dependencia de la Alta Consejería para la Equidad de la Mujer, como un organismo más de apoyo, aprobado en primer debate por la Comisión Primera de la Cámara de Representantes. Pero no existe la tipificación del delito de feminicidio para prevenir y erradicar situaciones que se caractericen como tales. Los autores de este artículo consideran, como lo dijo Diana E. Russell, que el uso del término femicidio (o feminicidio en términos de Lagarde) permite mostrar el daño causado con una acción criminal de ciertos hombres, y así se hará pensar a la sociedad y a los decisores políticos. El interés es poder incorporar en el lenguaje de hombres y mujeres el término y su concepto para trabajar políticas que reduzcan el pensamiento misogénico, no sólo con sanciones ejemplares, sino con políticas de reinserción y transformación de cultura.

Teniendo como referencia este marco interpretativo y los avances en la normatividad internacional y nacional, se reitera que las violencias en contra de las mujeres en los sistemas de poder sociosexual patriarcal y capitalista, se nutren de las relaciones de subordinación, opresión, explotación, exclusión e injusticia, y del juego de relaciones de poder entre los sexos, en las que el factor de riesgo es la diferencia sexual..$^{38}$

En Colombia "no existen cifras oficiales de feminicidios, pero fuentes de ONG estiman que alrededor de 1.250 mujeres son asesinadas cada año". ${ }^{39}$ Lo anterior se afirma por cuanto el Instituto Nacional de Medicina Legal (INML)

38 O. Sánchez Gómez. ¿Será que a las mujeres nos matan porque nos aman? Feminicidios en Colombia 2002-2009. http://www.casmujer.org/ index.php/wf-menucpanel/publicaciones/ítem /sera-que-a-las-mujeresnos-matan-porque-nos-aman-feminicidios-en-colombia-2002-2009. html?category_id=13. (11 septiembre, 2012).

39 N. García. Colombia: Feminicidio Invisible. http://antropologiadegenero. com/?p=4455- (23 septiembre, 2012). 
Tabla 1. Femicidio íntimo de pareja según circunstancia del hecho, Colombia 2004-2008

\begin{tabular}{|l|c|c|c|c|}
\hline \multicolumn{1}{|c|}{ Pareja o ex pareja } & Maltrato de pareja & Riña & Venganza & Total \\
\hline Amante & 2 & 0 & 0 & 2 \\
\hline Compañero(a) permanente & 22 & 1 & 0 & 23 \\
\hline Esposo(a) & 5 & 1 & 0 & 6 \\
\hline Ex esposo(a) & 2 & 1 & 1 & 4 \\
\hline Ex amante & 1 & 0 & 0 & 1 \\
\hline Ex novio(a) & 2 & 0 & 0 & 2 \\
\hline Novio(a) & 4 & 1 & 0 & 5 \\
\hline Total & 38 & 4 & 1 & 43 \\
\hline
\end{tabular}

Fuente. INML, 2009

Tabla 2. Femicidio íntimo de pareja según escenario y circunstancia del hecho, Colombia 2004-2008

\begin{tabular}{|c|c|c|c|c|}
\hline Escenario del hecho & Maltrato de pareja & Riña & Venganza & Total \\
\hline Vivienda & 25 & 3 & & 28 \\
\hline Vía pública (andén, puente, peatonal, etcétera). & 4 & 1 & & 5 \\
\hline Carretera (fuera de la ciudad) & 1 & & 1 & 2 \\
\hline Espacios terrestres al aire libre & 2 & & & 2 \\
\hline Áreas deportivas o recreativas & 1 & & & 1 \\
\hline Calle (autopista, avenida, dentro de la ciudad) & 1 & & & 1 \\
\hline Lugares de esparcimiento con expendio de alcohol & 1 & & & 1 \\
\hline Lugares de hospedaje (alojamiento en hoteles) & 1 & & & 1 \\
\hline Vehículo & 1 & & & 1 \\
\hline Zonas de actividades agropecuarias & 1 & & & 1 \\
\hline Total & 38 & 4 & 1 & 43 \\
\hline
\end{tabular}

Fuente. INML, 2009

utiliza un sistema de información en el que no hay discriminación en cuanto a razones de muerte de las mujeres. Además, la sociedad habla de homicidio y no de feminicidio, a pesar de que hay asesinatos de mujeres por ser mujeres. Entre el 2003 y el 2007 hubo 7.031 homicidios de mujeres, precisándose que 640 de ellas fueron asesinadas por actores al margen de la Ley, grupos que suelen demostrar su rechazo por las mujeres, y que las consideran inferiores. ${ }^{40}$ En el periodo 2004-2009 la cifra total de mujeres asesinadas ascendió a $6.603,{ }^{41}$ y para el 2011 el total reportado fue de 1.415 féminas. Sólo a manera de ejemplo se incluyen las tablas 1 y 2 con estadísticas construidas a partir de datos publica-

40 Casa de la mujer et. al. Informe violencia sexual y feminicidios en $\mathrm{Co}$ lombia. Documento presentado a Comisión Interamericana de Derechos Humanos. http://www.verdadabierta.com/archivos-para-descargar/ category/25-violencia-contra-mujeres?download $=342 \% 3$ Ainforme-sobre-violencia-sexual-y-feminicidios-en-colombia (23 octubre, 2008).

41 Instituto Nacional de Medicina Legal (INML). Forensis. Homicidio, capítulo 2. Aproximaciones a los conceptos de femicidio, feminicidio y homicidio en mujeres. http://www.medicinalegal.gov.co/images/stories/root/ FORENSIS/2009/Homicidios.pdf (25 abril, 2011). dos por el Instituto de Medicina Legal en su revista Forensis 2009 y 2011, en los que se observa que, a pesar de no existir la tipificación del delito, esa entidad gubernamental denomina los hechos como femicidios intimos. ${ }^{42}$

\section{B. Propuesta normativa para tipificar en Colombia el delito del feminicidio como figura autónoma}

\section{1. ¿Por qué feminicidio?}

Si bien es cierto feminicidio es un neologismo, su pretensión va más allá de la mera novedad en el uso de un término nuevo, porque, aunque el término homicidio se ha utilizado en forma universal al referir al asesinato de una persona independientemente de su género o

\footnotetext{
42 La clasificación de los tipos de femicidios se puede verificar en la página web Arte contra violencia de género. Tipos de feminicidio. http:// artecontraviolenciadegenero.org/? $\mathrm{p}=1614$ (31 diciembre, 2012).
} 
sexo, el sufijo "cidio" se encuentra en otras palabras que refieren el asesinato de casos particulares. Por ejemplo: genocidio (exterminación de gente); infanticidio (asesinato de niños o niñas); filicidio (asesinato de un hijo o una hija); suicidio (asesinato de sí mismo). Entonces, si la referencia es a la muerte de una fémina, debe emplearse el término feminicidio.

Para definir el término feminicidio se parte de sus raíces etimológicas. Las dos raíces latinas de la palabra que nos ocupan son fémina (mujer) y caedo, caesum (matar). La palabra en latín para mujer no es femena, sino fémina, con "i”. Al unirse dos palabras para formar otra, se respetan las raíces de las dos y no sólo se unen, sino que se pueden poner vocales de unión según el caso en el que estén las palabras. Por eso, se dice biología y no bioslogía y también homicidio y no homocidio. La "i" es una letra de unión de las dos palabras que viene de la tercera declinación del latín. Feminis quiere decir "de la mujer"; entonces la muerte de la mujer sería feminiscidium, y de allí pasamos a la palabra feminicidio, que es perfectamente correcta para el español. ${ }^{43}$

El feminicidio, por consiguiente, implica una conducta por parte de un agresor masculino quien por razones de género quebranta el derecho a la vida de una mujer. Es cierto que el crimen de odio contra las mujeres por ser mujeres suele ser el final de una espiral de violencia originada en la relación desigual entre ellas y los hombres bajo una sociedad patriarcal. $\mathrm{Mu}-$ jeres y hombres aprenden desde la infancia patrones diferenciadores por género, permitiendo, que los segundos se adjudiquen derechos y libertades no extendidos hacia las primeras. Por ello, la historia está llena de experiencias de mujeres oprimidas y sumisas, con aceptación de estas al considerar normal la condición de inferioridad. ${ }^{44}$

Monárrez Fragoso ${ }^{45}$ definió el feminicidio como la:

[...] progresión de actos violentos que van desde el maltrato emocional, psicológico, los golpes, los insultos, la tortura, la violación, la prostitución, el acoso sexual, el abuso infantil, el infanticidio de niñas, las mutilaciones

43 J. Monárrez. Feminicidio sexual serial en Ciudad Juárez. Debate Feminista, año 13, Vol. 25, abril 2002

44 Existen situaciones de violación; tortura; mutilación; esclavitud sexual; abuso sexual infantil incestuoso y extrafamiliar; maltrato físico y emocional; y acoso sexual, casos que fácilmente terminan en la muerte de las mujeres, sin que algunos gobiernos le hayan dado la dimensión que requiere; por el contrario, ciertas culturas legalizan y legitiman la violencia contra las mujeres.

45 J. Monárrez. Op. cit. genitales, la violencia doméstica y toda política que derive en la muerte de las mujeres, tolerada por el Estado.

Por su parte, Lagarde (2008, citada en INML $)^{46}$ lo define como un genocidio contra las mujeres

[...] [que] sucede cuando las condiciones históricas generan prácticas sociales que permiten atentados violentos contra la integridad, la salud, las libertades y la vida de niñas y mujeres. [...] Para que se dé el feminicidio concurren de manera criminal, el silencio, la omisión, la negligencia y la colusión parcial o total de autoridades encargadas de prevenir y erradicar estos crímenes. Su ceguera de género o sus prejuicios sexistas y misóginos sobre las mujeres.

En principio Russell ${ }^{47}$ habló del "femicidio" y lo definió como el asesinato de mujeres por hombres, por ser mujeres. Pero, que como lo dijera Monárrez Fragoso, ${ }^{48}$ en castellano hay que mencionarlo como feminicidio dado la etimología de la palabra. Para aquella autora, sólo si se denomina de manera diferente al homicidio se visibilizará la violencia constante contra las mujeres, y además se hará diferencia entre la muerte de una mujer por causas diferentes al odio que se les tenga en razón a su género. Precisamente, Lagarde también cambió el término de femicidio utilizado por Russell, con su autorización, por el de feminicidio, sin desconocer la esencia de la denominación inicial: homicidio de la mujer por su condición de ser mujer, como secuela de diferentes formas previas de violencia (violación sexual, riñas, repudio, hostigamiento, acoso, o abandono). La intención fue visibilizar una situación social mediante la homologación del lenguaje y la tipología del delito, en términos de modificación del ordenamiento jurídico a partir de los análisis que surgen en el campo de la academia.

Según la base de datos de Monárrez (citada por Atencio $)^{49}$ se distinguen tres tipos de feminicidios que a continuación se explicarán solo a manera de reseña: 1) íntimo, 2) sexual sistémico, y 3) por ocupaciones estigmatizadas. El primero corresponde al asesinato

46 Instituto Nacional de Medicina Legal (INML). Op. cit. 47 D. Russell \& J. Radford. Op. cit.

48 J. E. Monárrez. Peritaje sobre feminicidio sexual sistémico en Ciudad Juárez. Caso 12.498. "González y otras vs México". Campo Algodonero. http://www.corteidh.or.cr/docs/casos/expedientes/Mon\%C3\%A1rrez. pdf. (31 diciembre, 2012).

49 G. Atencio. Feminicidio-femicidio: un paradigma para el análisis de la violencia de género. http://www.feminicidio.net/index.php?option=com content\&view $=$ article\&id $=67 \&$ Itemid $=8$ (23 septiembre, 2012). 
realizado por quien tuvo relaciones íntimas, familiares, de convivencia o afines con la víctima. El segundo hace alusión a un asesinato acompañado de secuestro, tortura y violación. El tercero opera sobre mujeres quienes ocupaban su tiempo en actividades desautorizadas por la sociedad (incluso por las demás mujeres), tales como bailarinas, meseras, damas de compañía o prostitutas, quienes ejercen sus labores en horario nocturno o en sitios considerados peligrosos (bares, prostíbulos, clubes nocturnos......50

\section{Situación del feminicidio en Colombia}

En Colombia las cifras de casos de esta naturaleza convierten el problema en un asunto que requiere ser asumido desde los ámbitos político, jurídico, social y cultural, tanto desde lo local como desde lo internacional. Ello porque las cifras de maltrato a las mujeres por parte de sus parejas es alarmante. Hablar de 312.928 casos en ocho años (2001-2009) con mayor concentración en nueve departamentos del país, ${ }^{51}$ de los 89.807 casos de violencia intrafamiliar en el 2011 o de las 172 mujeres víctimas de asesinato ${ }^{52}$ luego de hechos de violencia intrafamiliar más otros cuya causa fue la misoginia con un porcentaje del $12,16 \%$, no pueden ser cifras que mantengan a la sociedad silenciosa.

La Mesa técnica de seguimiento y control a la Ley 1257 del 2008 presentó cifras de asesinatos en el 2010 así: 1.444 mujeres y 16.015 hombres. Con una condición: la violencia intrafamiliar sigue siendo el escenario más propicio para culminar en la muerte a mujeres, dado que un $72,23 \%$ (1.043) del total de las féminas víctimas, lo fueron como resultado esa tipología de violencia, siendo el sujeto activo su pareja o ex pareja. Al revisar las ocupaciones de las 1.043 víctimas de violencia intrafamiliar, se encuentra que 312 eran amas de casa, 140 eran estudiantes, 88 fueron comerciantes, 73 trabajaban en asuntos domésticos, 34 se dedicaban al trabajo sexual y de 396 mujeres no se tiene informa-

50 Cuando la víctima es prostituta, los victimarios justifican su conducta en el odio que despierta esa ocupación de "vender su cuerpo" por considerarla "pecaminosa", de "mala reputación", y un "mal ejemplo para la sociedad", al punto de que en la mente de los asesinos, e incluso de los demás miembros de la sociedad, surge la apreciación de que "se lo merecía", "ella se lo buscó por lo que hacía", "era una mala mujer", "su vida no valía nada". G. Atencio \& E. Laporta. Publicaciones etiquetadas con Ciudad Juárez. Tipos de feminicidio o las variantes de la violencia extrema patriarcal. http:// antropologiadegenero.com/?tag=ciudad-juarez (31 diciembre, 2012).

51 Antioquia, Bolívar, Bogotá D.C., Cauca, Chocó, Putumayo, Risaralda, Santander y Valle del Cauca.

$52 \mathrm{El}$ total de mujeres asesinadas en el 2011 fue de 1.415 . ción de su ocupación. Ello, sin contar las 17.000 mujeres sujetos pasivos de violencia sexual en el 2011 y las 59.952 víctimas de violencia infrafamiliar o doméstica. Datos que se toman de los informes del Instituto $\mathrm{Na}$ cional de Medicina Legal y Ciencias Forenses..$^{53}$ Dentro de esa mesa de seguimiento se hacen reflexiones sobre la falta de medidas de prevención de víctimas y el hecho de direccionar acciones en el tema de género y no de la especificidad de la mujer como ser humano con derechos. Es decir, la generalidad en el tema impide acciones efectivas en función de reducir las violencias contra las mujeres, como lo demuestran las cifras. Eso sí, algunas entidades estatales ${ }^{54}$ adelantan acciones en las que, parece ser, aumentan los estudios sobre responsabilidades estatales y de sus funcionarios, pero no reducen la violencia contra la mujer.

Precisamente, el gráfico 5 muestra que, a pesar de la existencia de la Ley 1257 del 2008, en el 2009, primer año de vigencia de la norma en comento, crecieron los hechos de violencia intrafamiliar. Si se compara con el 2008, el ascenso fue del $25 \%$, y si se compara con el año 2007, antes de la existencia de la Ley, subieron los casos en un 104\%. Ahora, entre el 2009 y el 2010, el incremento fue muy alto, dado que corresponde a un $85,26 \%$. Sin embargo, se mostró un descenso para el año 2011 en un 14\%.

Se reitera la consideración sobre no efectividad de una ley cuya intención pudo ser positiva, pero que no muestra resultados óptimos; mucho más al saber que entre enero y octubre del 2012 fueron atendidas en el INMLCF, por hechos de violencia intrafamiliar, 47.390 mujeres. ${ }^{55}$

Otras estadísticas que orientaron a los autores de este trabajo frente al tema del feminicidio fueron las encontradas en el Observatorio de Asuntos de Géne-

53 L. M. Cabrera. Informe de la Mesa por el derecho de las mujeres a una vida libre de violencias sobre la implementación de la ley 1257 del 2008 y su estado actual de cumplimiento. Corporación Sisma Mujer. http:// www.sismamujer.org/sites/default/files/publicaciones/1\%C2\%B0\%20 Informe\%20Mesa\%201257..pdf (15 septiembre, 2012).

54 Es cierto que aunque entidades como la Defensoría del Pueblo, la Procuraduría General de la Nación o incluso la misma Consejería para la Equidad de la Mujer realicen acciones orientadas a difundir la Ley y a sensibilizar distintos sectores de la sociedad, y tengan como fuente de consulta el Observatorio de Asuntos de Género de la Consejería, el problema sigue haciéndose más complejo por el elevado número de casos en los que las mujeres son víctimas, sin contar aquellos que no se registran o que se ignora si la causa de la muerte u otros hechos violentos fue por cuestiones misóginas. Precisamente, una de las preocupaciones de la mesa de seguimiento es la no consolidación de información, limitándose a los datos suministrados por el INMLCF.

55 El Tiempo (2012, 24 noviembre). En el 2012, 47 mil afectadas por violencia intrafamiliar. Redacción justicia. http://www.eltiempo.com/justicia/ ARTICULO-WEB-NEW_NOTA_INTERI OR12399406.HTML (16 diciembre, 2012). 


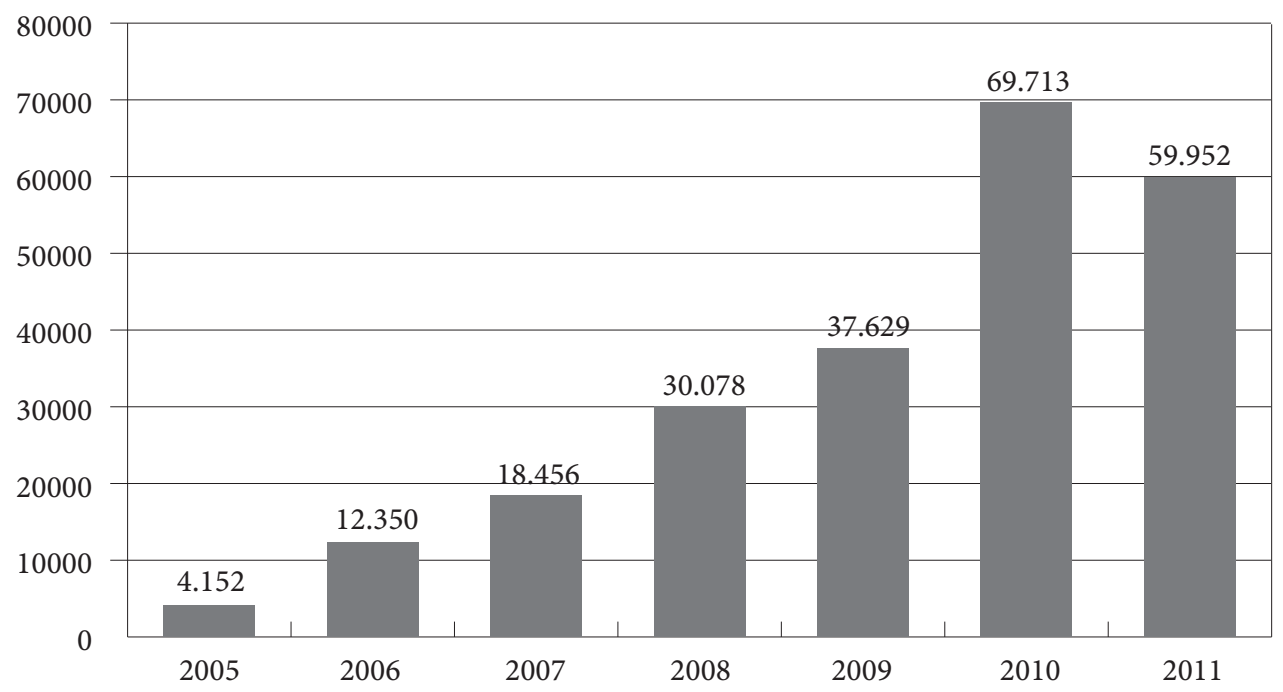

Gráfico 5. Comportamiento de casos de violencia intrafamiliar en Colombia Fuente. Cabrera, 2012, y adición de los autores

ro, Alta Consejería Presidencial para la Equidad de la Mujer y que se relacionan en la tabla 3.

De acuerdo con la tabla 3, hay un elevado índice de casos de feminicidio en Valle del Cauca, Bogotá, Antioquia, Santander y Cundinamarca. El lapso analizado estuvo, en algunos de los años incluidos, bajo la política de Seguridad Democrática; pero, infortunadamente, hubo inseguridad no sólo para la población rural, sino para mujeres, personas desplazadas, indígenas, negritudes y otras minorías.

Tabla 3. Muerte de mujeres en manos de su pareja o ex pareja íntima en Colombia, por departamento 2007-2011

\begin{tabular}{|c|c|c|c|c|c|c|c|}
\hline Departamento & 2007 & 2008 & 2009 & 2010 & 2011 & Total & $\%$ \\
\hline Antioquia & 7 & 19 & 11 & 9 & 11 & 57 & 10,3 \\
\hline Santander & 8 & 4 & 6 & 11 & 12 & 41 & 7,4 \\
\hline Atlántico & 5 & 3 & 4 & 9 & 9 & 30 & 5,4 \\
\hline Bolívar & 7 & 5 & 2 & 7 & 5 & 26 & 4,7 \\
\hline Meta & 5 & 2 & 8 & 8 & 3 & 26 & 4,7 \\
\hline N. de Santander & 2 & 6 & 2 & 3 & 2 & 15 & 2,7 \\
\hline Quindío & 9 & 2 & 1 & & 1 & 13 & 2,3 \\
\hline San Andrés & & & & 1 & 12 & 13 & 2,3 \\
\hline Caldas & 4 & 3 & 3 & 1 & 1 & 12 & 2,2 \\
\hline Huila & - & 4 & - & 3 & 5 & 12 & 2,2 \\
\hline Sucre & 1 & 3 & 2 & 3 & 3 & 12 & 2,2 \\
\hline
\end{tabular}


Viene

\begin{tabular}{|l|c|c|c|c|c|c|c|}
\hline Arauca & 3 & - & 3 & 4 & 1 & 11 & 2 \\
\hline Risaralda & 1 & 2 & 4 & 2 & 2 & 11 & 2 \\
\hline Boyacá & 1 & 2 & 5 & 1 & 1 & 10 & 1,8 \\
\hline Cauca & 1 & 1 & 4 & 2 & 2 & 10 & 1,8 \\
\hline Córdoba & 3 & 4 & - & 2 & 1 & 10 & 1,8 \\
\hline Magdalena & 1 & 3 & 1 & 1 & 2 & 8 & 1,4 \\
\hline La Guajira & 1 & 1 & - & 2 & 1 & 5 & 0,9 \\
\hline Caquetá & - & - & 1 & 2 & 1 & 4 & 0,7 \\
\hline Casanare & 2 & 1 & - & 1 & & 4 & 0,7 \\
\hline Putumayo & 1 & 1 & - & 1 & 1 & 4 & 0,7 \\
\hline Amazonas & 1 & - & - & 1 & & 2 & 0,4 \\
\hline S. J. Guaviare & - & 2 & - & & & 2 & 0,4 \\
\hline Vichada & & & & 1 & 1 & 2 & 0,4 \\
\hline Total & 118 & 108 & 102 & 125 & 101 & 554 & 100 \\
\hline
\end{tabular}

Fuente. Forero Martínez, $2012^{56}$

\section{Algunas posturas sobre la tipificación o no del feminicidio}

El Comité de América Latina y el Caribe para la Defensa de los Derechos de la Mujer (Cladem), generó un debate en el 2011 sobre el tema. Se estudiaron casos como los dos proyectos de ley de Panamá, ${ }^{57}$ uno de los cuales, el de la Defensoría del Pueblo, promovía el derecho de la víctima a atención médica, orientación, asesoramiento jurídico y asistencia técnica legal gratuitos, inmediatos y especializados, desde que se conoce el hecho, debiendo, en todo caso, el agresor asumir tales costos; mecanismos eficientes para denunciar a los funcionarios que incumplan plazos o incurran en otras irregularidades; ejecución de programas de formación continua para los servidores públicos ${ }^{58}$ a fin de que se sensibilicen y garanticen el cumplimiento de los objetivos de la ley; creación de unidades de fiscalías

56 L.Y. Forero. Muerte de mujeres en manos de su pareja o ex pareja íntima, según departamentos Colombia 2007-2011. https://exchange. camaradirecta.com/owa/ ae $=$ Item \& $\mathrm{t}=\mathrm{IPM}$. Note\&id $=$ RgAAAAAU1llV X9B5QJJqYVFVk1C5BwBXqC4UUMJ4QYLLAlJg\%2bsfHAAfiFS\%2b LAAAXvcxBXIPATpPTPoamv9WgAAAABBVkAAAJ (19 julio, 2012).

57 La Defensoría del Pueblo de Panamá preparó un proyecto y estableció protección hacia la mujer desde lo consagrado en los convenios internacionales de la Cedaw y Belém Do Pará, porque ese país cuenta con muchas leyes de protección a la mujer que no se han puesto en práctica eficazmente debido a fallas en las estrategias y en las políticas públicas para prevenir tal problema y para colocar el tema en el marco del respeto por los derechos humanos.

58 Con especial énfasis en los operadores(as) de justicia, el personal de salud y las autoridades de policía. y órganos jurisdiccionales especializados en el tema de violencia contra la mujer; creación de centros de acogida por provincia para que las mujeres solicitaran ayuda y protección; políticas públicas de sensibilización y prevención que involucran a los municipios, en donde también se deben capacitar en el tema; entre otras medidas interesantes. ${ }^{59}$ En realidad, la preocupación de los debatientes giró alrededor de la efectividad de un tipo penal independiente, y por ello llevaron a colación las posturas de Toledo Vásquez sobre una efectividad desde lo cultural y simbólico, que requiere implementar políticas públicas conexas. Toledo Vásque ${ }^{60}$ habla de la difícil relación entre las distintas formas de violencia contra las féminas y las leyes criminales. Dijo ella que "los países latinoamericanos adoptaron las normas civiles y penales de los Estados conquistadores y, con ellas, todo un sistema jurídico destinado a asegurar la subordinación de las mujeres" para mantener la dominación machista heredada de la cultura dominante, dado que existieron disposiciones

59 C. Antony. Contribuciones al debate sobre la tipificación penal del feminicidio/femicidio. Ramírez M. E. Programa mujeres y derechos tribunal de mujeres y DESC CLADEM, Colombia ILSA. Re: Informe monitoreo de feminicidio año 2008. https://exchange.camaradirecta. com/owa/?ae $=$ Item $\& \mathrm{t}=$ IPM.Note\&id $=$ RgAAAAAU1llVX9B5QJJqYVF Vk1C5BwAFKQnbT10aQYV8pT0F4ZYfAAAStAq6AABdoi4083XRQZ 5wCqUFQUN\%2fAAAAAEDNAAAJ (2012, octubre 12).

60 P. Toledo. El derecho penal frente a la violencia contra las mujeres. Feminicidio. Consultoría para la oficina en México del Alto Comisionado de las Naciones Unidas para los derechos humanos. México: OACNUDH. (2009). 
tanto penales como civiles permisivas en cuanto al derecho del marido de corregir a su esposa.

La cuestión, siguiendo a los debatistas, era no crear tipos penales abiertos, porque no son garantistas. Toledo Vásquez ${ }^{61}$ insiste en que una conducta frente al tema del feminicidio debe tener una descripción clara para que no sea indeterminada, porque se corre el peligro de una vulneración al principio de legalidad frente a las "normas relativas a la violencia contra las mujeres y, en particular, el femicidio o feminicidio. Carcedo (citada por Antony) ${ }^{62}$ también recomienda sobre la forma de enunciar el tipo penal, para evitar su ambigüedades; por ejemplo:

- Usar un término preciso, que delimite.

- No puede ser una definición taxativa cerrada a priori, siempre pueden surgir formas nuevas.

- La relación de pareja, familiar y el ataque sexual son contextos de femicidios en todas las sociedades.

- Para determinar si un homicidio de mujer es femicidio/feminicidio se requiere conocer quién lo comete, cómo lo hace y en qué contexto (no siempre se tiene toda la información, pero hay indicadores).

- Un criterio básico (no único): si el hecho de ser la víctima una mujer es necesario para que el asesinato se dé.

Otro aspecto de especial consideración, desde la misma autora, es lo relacionado con la posibilidad de comisión de femicidios/feminicidios por parte del Estado: por ej. muertes maternas, y abortos con resultado de muertes maternas (aquí se tendría que analizar si son causada por misoginia o discriminación).

El primer Código Penal que incluyó una conducta priorizando la condición de mujeres víctimas de violencia fue el sueco; en 1998 introdujo el tipo penal "grave violación de la integridad de la mujer" con la consideración de ser una conducta en la que el sujeto activo solo puede ser un hombre. En España, 2004, se agravó la sanción de varias conductas delictuales cuando fueron cometidas contra mujeres por parte de sus parejas actuales o pasadas. ${ }^{63}$

El Mecanismo de Seguimiento de la Implementación de la Convención Interamericana para Prevenir, Sancionar y Erradicar la Violencia contra la Mujer

61 Ídem.

62 C. Antony. Op. cit.

63 P. Toledo. Op. Cit.
(MESECVI), ${ }^{64}$ insiste en que las normas relacionadas con la violencia contra las mujeres deben ser específicas y no neutras en cuestión de género. El Comité encontró que "el femicidio sigue siendo un tema ausente de la mayoría de Estados parte" 65 por cuanto algunos lo hacen formar parte de las normas sobre violencia, ${ }^{66}$ aun cuando aparezca tipificada tal conducta. Se insiste en que el feminicidio/femicidio debe visibilizarse y deben establecerse medidas para prevenir y sancionar su comisión. Incluso, reitera la necesidad de mirar más allá del llamado feminicidio íntimo, y no dejar a la deriva los casos ocurridos en el ámbito de lo público, recomendando que las normas penales sancionen también conductas cometidas por comunidad, por otros conocidos o por funcionarios públicos. ${ }^{67}$

Quienes censuran la existencia de normas que regulen en forma individualizada la violencia contra la mujer y en particular el asesinato de estas, consideran que viola la igualdad formal. ${ }^{68},{ }^{69} \mathrm{La}$ doctrina penal cuestiona los tipos específicos frente al género y por ello mantiene en ciertas legislaciones el agravante del homicidio, para evitar un derecho penal de autor (hombres únicamente). Esa igualdad formal implica que la ley penal protege y se aplica a todos y todas por igual y bajo dos principios: trato igual a los iguales y trato desigual a los desiguales. Sobre este aspecto, vale la pena traer al escenario de discusión la postura del Tribunal Constitucional de España en la conocida Sentencia TC-59 del 14 de mayo del 2008, para quienes el asesinato o violencias contra la mujer por el hecho de ser mujer y cometidas por el hombre son evidencia de la desigualdad y del abuso de poder de que suelen ser objeto las mujeres.

64 También denominado Mecanismo de Seguimiento de la Convención de Belém Do Pará (MESEcvi). Este Mecanismo consiste en un sistema de evaluación a cargo de un comité integrado por expertos y expertas independientes para examinar el cumplimiento de los objetivos de la Convención por parte de los Estados parte. Se financia por contribuciones de los Estados parte y otros donantes, así como por la Comisión Interamericana de Mujeres de la oea.

65 Mecanismo de Seguimiento de la Convención de Belém do Pará (MESECVI). Legislación sobre Femicidio. Segundo Informe Hemisférico sobre la Implementación de la Convención de Belém do Pará. oEA. (2012).

66 Salvo el caso de Guatemala que tiene su propia ley para tratar el tema del feminicidio, acompañado de disposiciones sobre política pública complementaria.

67 MESECVI, Op. cit.

68 En Guatemala y en España hay opositores académicos a la tipificación del feminicidio como tal.

69 P. Toledo. Op. cit. 
El Tribunal Constitucional de España expresó que el delito del feminicidio no afecta el principio de igualdad entre hombres y mujeres ante la ley, dado el grado de superioridad de los hombres sobre las mujeres en cuanto a agresiones se refiere. El artículo 14 de la Constitución de España, contentivo del principio de igualdad, alude a un tratamiento diferenciado con supuestos de hecho iguales cuando hay justificación objetiva y razonable que no depare consecuencias desproporcionadas. Tal Sentencia se profirió para definir sobre la constitucionalidad de la Ley Orgánica de Medidas de Protección Integral contra la Violencia de Género, al entender la manifestación del dominio del hombre sobre la mujer, quien con conductas violentas vulnera el derecho a la vida, integridad física, libertad y dignidad de esta. Entonces, para el Tribunal Constitucional el legislador protegió tales derechos de las mujeres y también dejó sentado un precedente frente a la no violencia contra ellas.

No hay reproche a la postura del legislador al considerar el mayor daño cuando la víctima es una mujer y el victimario un hombre en el ámbito de pareja; por el contrario, la agresión a las mujeres por parte de su cónyuge, compañero permanente u hombres con quienes aquellas mantuvieron relaciones análogas, debe ser mayormente censurada por el ámbito relacional en el que se produce y con espacio para una arraigada desigualdad. Hoy, se conoce, una pauta cultural generadora de gravísimos daños a las mujeres víctimas con acción o acciones tan violentas por parte de los hombres, que representan un desvalor de la propia y personal conducta de estos: la inserción de aquella en una concreta estructura social a la que el mismo hombre coadyuva. $^{70}$

En ese estado de cosas, tipificar el feminicidio como un delito autónomo ${ }^{71}$ es crear protección a las mujeres respecto a agresiones por parte de sus parejas o ex parejas masculinas. Agresiones que, se repite, constituyen vulneración de la mujer en estado de subordinación y por ende no en situación de igualdad frente al hombre, lo cual no viola el principio de igualdad formal constitucional, sino que constituye un trato desigual a los desiguales, permitido por normas constitucionales de cualquier Estado medianamente democrático. Además,

70 España. Tribunal Constitucional. Sentencia tc-59 (2008, mayo 14) http://online.lexnova.es/servicesLXOL/visordoc? signatura $=5$ A713E298 16FAF638C9C12E4666BEB62\&titulacion $=(5$ enero, 2013).

71 Centro de Información y Desarrollo de la Mujer (cidem). Delito de feminicidio. http://cidem-ac.org/docs/feminicidio.pdf. (26 diciembre, 2012). el legislador penal goza de libertad de opción en sus previsiones punitivas, sin que ello conduzca a consecuencias desproporcionadas. De ahí que pueda penalizar la conducta consciente de agresión por parte del hombre a la mujer en el contexto de una relación sentimental, pero, se insiste, esas condiciones de desigualdad en las que se encuentran las mujeres sometidas a tratos crueles y violentos por parte de sus parejas hombres, siendo entonces permisivo para el legislador establecer un trato diferencial cuando la violentada es la mujer. Si mujeres y hombres no son iguales en el plano de la violencia de género no pueden serlo ante el tratamiento de la ley.

Otro aspecto a tratar frente al debate de la tipicidad del feminicidio es la condición de mayor gravedad de la pena. Toledo Vásquez ${ }^{72}$ manifiesta que si existieren los delitos neutros y el feminicidio con una sanción penal similar a los otros, no tendría razón de ser este delito autónomo. Entonces:

[...] es posible considerar que la lesividad adicional que contienen conductas como el femicidio/feminicidio sexual o el femicidio sexual sistémico, a pesar de que pueden ser reconducidas a un conjunto de delitos independientes, su gravedad como fenómeno no resulta contenido adecuadamente en ellas.

Mantener las mismas penas por hombres víctimas y mujeres víctimas es igual que mantener normas neutrales que no hacen la diferencia. La sugerencia es que se trate de una penalidad considerable, como sucede en España con la Ley Orgánica 1-2004 (Medidas de protección integral contra la violencia de género) que sanciona con mayor gravedad cuando ciertas conductas hayan sido cometidas por un hombre contra una mujer con quien se tiene o tuvo relaciones de afectividad. Una norma que, a pesar de las diferentes censuras ante la presunta inconstitucionalidad, ha sido defendida por el Tribunal Constitucional, como se explicó en párrafos anteriores. Y es que el tema del parentesco ha jugado un rol en el campo criminal, al punto que otorga: su mayor severidad [justificada] en el plus del injusto o mayor antijuridicidad en el hecho de atentar contra una persona de la que se es pariente o con quien se está casado - o se tiene una relación de convivencia-, pues en estos casos se vulnerarían además ciertos especiales deberes de cuidado y respeto originados en el derecho civil o incluso amparados constitucionalmente. ${ }^{73}$

\footnotetext{
72 P. Toledo. Op. cit. pág. 63.
}

73 Ídem. 
Por ende, se concluye, que sí se justifica el feminicidio como delito penal autónomo en Colombia, porque se atenta contra más de un bien jurídico con "conductas discriminatorias violentas en un ámbito concreto". ${ }^{74}$ Hay mayor antijuridicidad que debe comprometer al Estado tanto desde lo constitucional como desde lo legal, con la justificación de no estarse ante una discriminación positiva. Claro, no será la ley penal la que evite las muertes, porque el problema radica en la despolitización que pueda tener la sola tipificación. Como se lee en el debate Cladem, ${ }^{75}$ el problema radica en el precario acceso a la justicia por parte de las mujeres víctimas y en la existencia de un sistema judicial no consciente de los peligros que significa su falta de claridad sobre el nivel de vulnerabilidad de las mujeres violentadas, quienes por la desprotección tiene su vida en riesgo y con la opción de la impunidad según el direccionamiento judicial a las conductas de sus agresores.

\section{Posiciones de los convenios internacionales}

Existen tratados internacionales que se han ocupado de la protección hacia la mujer contra toda forma de violencia, e incluso que declararon la vida de las mujeres libre de violencia como un derecho fundamental. Por ejemplo: la Convención para la eliminación de todas las formas de discriminación contra las mujeres (CEDAW) ${ }^{76}$ adoptada en 1979 por la Asamblea General de las Naciones Unidas, junto con la Declaración sobre eliminación de la violencia contra la mujer, cuyo protocolo facultativo se formuló en 1999; la Segunda Conferencia Mundial de la mujer en Copenhague realizada en $1980 ;{ }^{77}$ la Tercera Conferencia Mundial de la mujer en Nairobi reunida en $1985 ; ;^{78}$ la Conferencia Mundial de los Derechos Humanos de 1993 en Viena; ${ }^{79}$

\footnotetext{
74 P. Toledo. Op. cit. pág. 72.

75 C. Antony. Op. cit.

76 En esta convención se define la discriminación contra la mujer como “[...] cualquier distinción, exclusión o restricción basada en el sexo que tenga por objeto o por resultado menoscabar o anular el reconocimiento, goce o ejercicio por la mujer, independientemente de su estado civil, sobre la base de la igualdad del hombre y la mujer, de los derechos humanos y las libertades fundamentales en las esferas política, económica, social, cultural y civil o en cualquier otra esfera" (art. 1).

77 Allí se adoptó una resolución sobre la mujer maltratada y la violencia en la familia.

78 En la que se reconoció la necesidad de eliminar la violencia contra las mujeres y contra las familias.

79 Evento en el que se reconoció que los derechos específicos de las niñas y las mujeres son derechos inalienables, y que era necesario elimina toda forma de violencia contra las féminas, entre ellas el acoso, por ir en
}

la Convención de Belém Do Pará de 1994 o Convención Interamericana para prevenir, sancionar o erradicar la violencia contra la mujer, acordada en Brasil..$^{80}$ Acuerdos que comprometen al Gobierno colombiano según el artículo 93 de la Constitución Política, en el que se indica que "Los tratados y convenios internacionales ratificados por el Congreso, que reconocen los derechos humanos y que prohíben su limitación en los estados de excepción, prevalecen en el orden interno". Bloque de constitucionalidad extendido a los aspectos de interpretación al mencionarse que "Los derechos y deberes consagrados en esta Carta, se interpretarán de conformidad con los tratados internacionales sobre derechos humanos ratificados por Colombia".

Es así como, en cumplimiento de esta obligación, los Estados deben actuar con la debida diligencia para prevenir, investigar y sancionar las violaciones a los derechos humanos de las mujeres, según lo consagra el artículo $7^{\circ}$ de la Convención de Belém do Pará, ratificada por Colombia mediante la Ley 248 de 1995. El artículo $3^{\circ}$ de la Convención habla de la protección del derecho de toda mujer a "una vida libre de violencia, tanto en el ámbito público como en el privado", a fin de respetar su vida, su libertad, su integridad física, psíquica y moral, entre otros importantes derechos. Obvio, todos ellos protegidos bajo el imperio de la ley y de la Constitución. El artículo 7o, literal c), por su parte, señaló que los Estados parte deben "incluir en su legislación interna normas penales, civiles y administrativas, así como las de otra naturaleza que sean necesarias para prevenir, sancionar y erradicar la violencia contra la mujer y adoptar las medidas administrativas apropiadas que sean del caso". En Colombia sí se han producido leyes que abordan el tema de la erradicación de la violencia; sin embargo, el Comité que lleva el seguimiento de la efectividad y aplicación de la Convención de Belem Do Pará puso en evidencia, en su Segundo Informe, el hecho de que Colombia es uno de los países donde se agrava el homicidio cuando se comete contra una mujer por el hecho de ser mujer, pero no se ha tipificado como es la expectativa existente.

Entonces, en los tratados internacionales existe ese compromiso colombiano de tipificar el feminicidio y de desarrollar funciones y actividades para proteger un

contra de su dignidad humana.

80 Tiene el propósito de proteger los derechos humanos de las mujeres y eliminar las situaciones de violencia que puedan afectarlas, ya que toda mujer tiene derecho a una vida libre de violencia, tanto en el ámbito público como en el privado. 
bien jurídico como es la vida de las mujeres, sean adultas o menores de edad. Lozano (2007, citado por Sánchez Gómez ${ }^{81}$ consideró que los Estados pueden tener:

[...] responsabilidad internacional no solamente por la falta o defecto de diligencia a la hora de prevenir los actos lesivos dirigidos contra los bienes o intereses internacionalmente protegidos, sino también por no reprimir esos actos, o en su caso, por no perseguir y castigar a los culpables de tales hechos.

Sánchez Gómez ${ }^{82}$ dice que desde el derecho internacional Colombia tiene una obligación de resultado que lo compromete, aun cuando haya hecho algunos esfuerzos, dado que sigue presentándose violencia contra las mujeres por el hecho de ser mujer.

En este sentido, pese a que el Estado colombiano ha ratificado la Convención para la Eliminación de todas las formas de Discriminación en contra de las Mujeres (CEDAW) y ha suscrito otros acuerdos internacionales y regionales para la protección de la mujer contra la violencia, entre estos la Convención Interamericana para Prevenir, Sancionar y Erradicar la violencia en contra de las Mujeres (Convención de Belém do Pará), aprobada y ampliamente ratificada en 1995, no ha reformado suficientemente la legislación para hacerla coherente con estos compromisos internacionales ni ha establecido reglamentos y suministrado financiación para la aplicación adecuada de los acuerdos internacionales o las políticas nacionales existentes que rechazan las violencias en contra de las mujeres. Entre los deberes inmediatos que los Estados tienen que cumplir respecto a la Convención de Belém do Pará está el de "actuar con la debida diligencia para prevenir, investigar y sancionar la violencia en contra de las mujeres" (art. 7, b). En este deber está incluido el conocer e investigar los patrones de violencia que afectan a las mujeres, como es el caso de los feminicidios. ${ }^{83}$

\section{Si existía un proyecto de Ley, ¿por qué se trabajó en una nueva propuesta?}

La pregunta podría generar una simple respuesta, pero exige profundizar sobre ciertos aspectos que acompañó al grupo de investigación, dado que el objetivo primordial del trabajo investigativo consistió en es-

\footnotetext{
81 O. Sánchez. Op. cit. pág. 32.

82 Ídem.

83 O. Sánchez. Op. cit. pág. 34.
}

tructurar un proyecto de ley para tipificar el delito del feminicidio como figura autónoma en Colombia, de acuerdo con un función garantista del Estado. Entonces, siguiendo el artículo $8^{\circ}$ de la Convención de Belém do Pará, se propuso como resultado de la investigación que aquí se comenta, un proyecto, que a diferencia del Rosa Elvira Cely, incluye medidas que ayuden a construir otro imaginario frente a los derechos de la mujer libre de violencia; normas de sensibilización tanto a la comunidad y sociedad en general, como en particular a los funcionarios responsables de conocer y sancionar los hechos infractores por cuestiones de género y en particular contra la mujer. Ello porque el problema complejo del feminicidio en sus diferentes modalidades hay que mirarlo más allá de un caso de violencia de género; la cuestión es superar los prejuicios y sensibilizar a hombres y mujeres sobre la trascendencia social del asunto, para abordarlo de manera sistémica como parte de un tema que exige lecturas precisas. Se conoce de víctimas de violencia que temieron denunciar por miedo al agresor y su situación terminó en su muerte; o de los casos donde sí denunciaron y no hubo respuesta efectiva de los competentes para hacerlo. Por consiguiente, la cuestión es no quedarse en cifras sino trabajar para sensibilizar.

El proyecto de ley radicado el 1 de agosto del $2012^{84}$ no planteaba una unidad de fiscalía especializada para atender estos casos, ni proponía, en concepto de los autores, cómo erradicar efectivamente las violencias contra las mujeres. Además, en esta propuesta nueva se enfatiza en el tema de reinserción social de los sujetos activos del delito, entendiendo como su oportunidad de fortalecer redes de apoyo en el marco de la corresponsabilidad social, en donde las entidades del Estado, la empresa privada, la familia y la sociedad civil se unan para ofrecer oportunidades que disminuyan el riesgo de reincidencia. ${ }^{85}$

El proyecto "Mujer con Justicia" tiene como plus el énfasis en el trabajo con el victimario para propiciar

84 A diciembre del 2012 se encontraba en la Comisión Primera Constitucional, sin que hubiera entrado a primer debate. A la fecha de la revisión del presente artículo se encuentra que fue archivado el 24 de junio del 2013, en aplicación del artículo 190 de la Ley 5 de 1992, que a su tenor dice: "Artículo 190. Tránsito de legislatura. Los proyectos distintos a los referidos a leyes estatutarias que no hubieren completado su trámite en una legislatura y fueren aprobados en primer debate en alguna de las Cámaras, continuarán su curso en la siguiente en el estado en que se encontraren. Ningún proyecto será considerado en más de dos legislaturas”.

85 R. Martínez. Pautas vigencia 2012 servicio pospenitenciario. http:// www.inpec.gov.co/portal/page/portal/Inpec/Institucioninpec/PlanesInstitucionales/ReinsercionSocial (13 octubre, 2012). 
en él un pensamiento libre de violencia y su comprensión de que la mujer y el hombre son iguales, sin que alguno sea más que el otro; es decir, el proyecto quiere apoyar un cambio en la personalidad de los pueblos (inconsciente colectivo) como resultado de la modificación cultural. Por su extensión no es viable publicarlo en esta Revista, pero se invita a los estudiosos del tema para que lo consulten en la Biblioteca de al Universidad Cooperativa de Colombia.

\section{CONCLUSIONES}

La situación en los seis países hispanoparlantes de América Latina revisados muestra que, a pesar de sus diferencias en el campo de lo jurídico, se vive un fenómeno de violencia contra la mujer por ser mujer bajo situaciones similares. Se habla de diferencias en el campo de lo jurídico, porque sólo en Guatemala, México, Costa Rica, Perú y Chile se encuentra tipificada la conducta penal del feminicidio, cada uno con su propia característica, sin desconocer que en Colombia hay una condición de agravación al delito del homicidio cuando se presenta la figura de la muerte de la mujer a manos de su pareja, por el hecho de ser mujer.

La tipificación de un delito autónomo denominado feminicidio no es una cuestión de moda o de uso interesante de neologismos, sino la respuesta a la necesidad de visibilizar un grave problema que afecta a generaciones presentes y futuras. Por ello, desde el derecho internacional público, se ha considerado indispensable tipificar el delito de feminicidio y desarrollar funciones y actividades que protejan la vida de las mujeres, con acciones preventivas y sancionatorias. Hay, como lo dijo Sánchez Gómez, ${ }^{86}$ una obligación de resultado en cabeza del Estado colombiano, para trabajar efectivamente en pro de la eliminación de las violencias contra las féminas. ${ }^{87}$

86 O. Sánchez. Op. cit.

87 Mediante la Ley 984 del 12 de agosto del 2005, Colombia aprobó el Protocolo facultativo de la Convención sobre eliminación de todas las formas de discriminación contra la mujer. Verificar en: Colombia. Congreso de la República. Ley 984 (2005, agosto 12). Por medio de la cual se aprueba el "Protocolo facultativo de la Convención sobre la eliminación de todas las formas de discriminación contra la mujer", adoptado por la Asamblea General de las Naciones Unidas el seis (6) de octubre de mil novecientos noventa y nueve (1999). http://www. secretariasenado.gov.co/senado/basedoc/ley/2005/ley_0984_2005.html. (17 febrero, 2012)
Siendo el feminicidio una conducta pluriofensiva, dado que vulnera de manera violenta diversos bienes jurídicamente tutelados: la vida y la integridad personal, las personas protegidas por el DIH, la libertad individual y autonomía personal, la libertad, integridad y formación sexuales y la familia, no se requieren circunstancias de agravación punitiva y por ello no se incluyó tal condición en la propuesta. El feminicida no permite ni comparte el desarrollo de la víctima de manera libre, independiente y voluntaria al considerarla un objeto más en su vida que debe estar subordinada a su libre disposición. Incluso, por el rol de madre, hija o hermana que cumplía la víctima, al arrebatarla en forma violenta del seno de su hogar se causan secuelas irreparables en los demás miembros de la familia. Por consiguiente, el feminicidio no puede ser señalado como el resultado del asesinato sobre una mujer, sino que debe ser visto como una acción que afecta diversos bienes que el legislador ha decidido proteger toda vez que guardan una relación entre sí.

En el ordenamiento jurídico colombiano sí existen disposiciones que determinan direccionamientos hacia la reinserción social de los delincuentes, pero englobadas de una forma general a todas las personas sancionadas con penas privativas de la libertad en establecimientos carcelarios. Por consiguiente, se evidencia la necesidad de trabajar con los sujetos activos de los delitos violentos cometidos contra la mujer como lo es el feminicidio y para ello es necesario sustentar proyectos o programas con estudios que determinen las condiciones tipológicas de los sujetos activos del delito que se tipificará una vez aprobado el proyecto de ley. Es decir, se requieren medidas jurídicas y sociales que contribuyan a reducir las violencias contra las mujeres. Por ende, un aspecto central en el proyecto de ley "Mujer con Justicia" es fortalecer la reinserción de los sujetos activos previo cambio de su imaginario, a fin de que entidades como el Inpec, entre otras, puedan cumplir con su función para que estos hombres entiendan que la sociedad sufre enormes perjuicios generacionales al permitirse que se le quite la vida a mujeres hijas, mujeres madres, mujeres hermanas, mujeres esposas o mujeres amantes.

Asimismo, se deben fortalecer las redes de apoyo que ofrezcan mejores oportunidades de vida a los victimarios y propender por concretar la corresponsabilidad entre Estado, sociedad y familia como comprometidos con los cambios del inconsciente colectivo. Las y los colombianos no pueden continuar desconociendo un complejo problema que requiere medidas efectivas para reducir los hechos violentos contra las mujeres. 


\section{REFERENCIAS}

Arte contra violencia de género. Tipos de feminicidio. http:// artecontraviolenciadegenero.org/?p=1614 (31 diciembre, 2012).

B. Pedroza. Discriminación, violencia de género y crisis económica en América Latina. Crisis económica: una perspectiva feminista desde América Latina, págs. 179-202. Instituto de Investigaciones Económicas, Universidad Nacional Autónoma de México, Centro de Estudios de la Mujer (CEM) de la Universidad Central de Colombia y Consejo Latinoamericano de Ciencias Sociales. (2010).

C. Antony. Contribuciones al debate sobre la tipificación penal del feminicidio/femicidio. M. E. Ramírez Programa mujeres y derechos tribunal de mujeres y DESC CLADEM, Colombia ILSA. Re: Informe monitoreo de feminicidio año 2008. https://exchange.camaradirecta.com/ owa/?ae=Item\&t=IPM.Note\&id=RgAAAAAU1llVX9 B5QJJqYVFVk1C5BwAFKQnbTl0aQYV8pT0F4ZYfAAAStAq6AABdoi4083XRQZ5wCqUFQUN\%2fAAAA AEDNAAAJ (2012, octubre 12).

C. Rojas \& K. Herrera. (2009). Análisis sobre la eficacia de los tipos penales especiales que introduce la Ley de Penalización de la violencia contra las mujeres, enfocado a los delitos contra la integridad física de las personas y su constitucionalidad. pág. 213. Costa Rica: Universidad de Costa Rica, Facultad de Derecho. www.iij.ucr.ac.cr/ download/file/fid/305-. (23 septiembre, 2012).

Casadelamujeret.al.InformeviolenciasexualyfeminicidiosenColombia. Documento presentado a Comisión InteramericanadeDerechosHumanos.http://www.verdadabierta.com/ archivos-para-descargar/category/25-violencia-contramujeres? download $=342 \% 3$ Ainforme-sobre-violenciasexual-y-feminicidios-en-colombia (23 octubre, 2008).

Centro de Información y Desarrollo de la Mujer (CIDEM). Delito de feminicidio. http://cidem-ac.org/docs/FEMINICIDIO.pdf. (26 diciembre, 2012).

Centro de la Mujer Peruana Flora Tristán. Reporte feminicido en el Perú. http://www.flora.org.pe/investigaciones/ feminicidio.pdf (23 septiembre, 2012).

Chile. Biblioteca del Congreso Nacional.Ley No. 20.066(2005, septiembre 21). Establece ley de violencia intrafamiliar. http://www.leychile.cl/Navegar?idNorma=242648 (22 septiembre, 2012).

Chile. Biblioteca del Congreso Nacional. Ley No. 20.480. (2010, diciembre 14). Por medio de la cual se modifica el Código Penal y la Ley No. 20.066 sobre violencia intrafamiliar, estableciendo el "Femicidio" aumentando las penas aplicables a este delito y reforma las normas sobre parricidio. http://www.leychile.cl/ Navegar?idNorma=1021343 (22 septiembre, 2012).
Chile. Servicio Nacional de la Mujer. http://portal.sernam. $\mathrm{cl} /$ ?m=programa\&i=15-Servicio Nacional de la mujer -gobierno de chile - feminicidio - 2008 (22 septiembre, 2012).

Circuito Nacional de Femicidio. Red de asistencia a víctimas. Informe anual año 2011, Protocolo intersectorial de atención a víctimas de feminicidio. http://www.apoyovictimas.cl/wp-content/uploads/2012/04/InformeCicuito-de-Femicidio-a\%C3\%B1o-2011.pdf (21 julio, 2012).

Colombia. Congreso de Colombia. Ley 1257 (2008, diciembre 4). Por la cual se dictan normas de sensibilización, prevención y sanción de formas de violencia y discriminación contra las mujeres, se reforman los Códigos Penal, de Procedimiento Penal, la ley 294 de 1996 y se dictan otras disposiciones. http://www.secretariasenado.gov.co/senado/basedoc/ley/2008/ley_1257_2008. html. (23 septiembre, 2012).

Colombia. Congreso de la República. Ley 248 (1995, diciembre 29). Por medio de la cual se aprueba la Convención Internacional para prevenir, sancionar y erradicar la violencia contra la mujer. http://www.elabedul.net/ Documentos/Leyes/1995/Ley_248.pdf- (23 septiembre, 2012).

Colombia. Congreso de la República. Ley 294 (1996, julio 16). Por la cual se desarrolla el artículo 42 de la Constitución Política y se dictan normas para prevenir, remediar y sancionar la violencia intrafamiliar. http://www. secretariasenado.gov.co/senado/basedoc/ley/1996/ ley_0294_1996.html (23 septiembre, 2012).

Colombia. Congreso de la República. Ley 48 de 1995 (1996, julio 16). http://www.secretariasenado.gov.co/senado/ basedoc/ley/1996/ley_0294_1996.html. (23 septiembre, 2012).

Colombia. Congreso de la República. Ley 599 Código Penal (2000, julio 24). http://www.secretariasenado.gov. co/senado/basedoc/ley/2000/ley_0599_2000.html. (23 septiembre, 2012).

Colombia. Congreso de la República. Ley 906 (2004, agosto 31). Por la cual se expide el código de procedimiento penal. http://www.secretariasenado.gov.co/senado/basedoc/ley/1996/ley_09060_204a..html. (23 septiembre, 2012).

Colombia. Congreso de la República. Ley 984 (2005, agosto 12). Por medio de la cual se aprueba el "Protocolo facultativo de la Convención sobre la eliminación de todas las formas de discriminación contra la mujer", adoptado por la Asamblea General de las Naciones Unidas el seis (6) de octubre de mil novecientos noventa y nueve (1999). http://www.secretariasenado.gov.co/senado/ basedoc/ley/2005/ley_0984_2005.html. (17 febrero, 2012). 
Colombia. Corte Suprema de Justicia. Proceso No. 27839 (2008, diciembre 2). http://www.usergioarboleda.edu. co/derecho_penal/jurisprudencia_cuarto_trimestre_2008.htm. (22 septiembre, 2012).

Colombia. Corte Suprema de Justicia. Proceso No. 38607 (2012, mayo 5). www.dmsjuridica.com/.../SALA.../2012/ mayo/38607(02-05-12).doc. (22 septiembre, 2012).

Costa Rica. Expediente 04-001884-0007-CO.

D. Russell \& J. Radford (2006). Feminicidio. La política del asesinato de las mujeres. http://books.google.com/book $s ? \mathrm{id}=\mathrm{Aq} 1 \mathrm{yKJQFjLYC \& printse}=$ frontcover\&source $=\mathrm{g}$ bs_ge_summary_r\&cad $=0 \# \mathrm{v}=$ onepage $\& \mathrm{q} \& \mathrm{f}=$ false $(10$ febrero, 2011).

E. Bräth. Feminicidios en México. Organizaciones de derechos de las mujeres y derechos humanos luchan contra la "cultura del silencio". http://www.boell-latinoamerica.org/downloads/HBs-Feminicidios_MC.pdf. (15 septiembre, 2012).

E. Bräth. Feminicidios en México. Organizaciones de derechos de las mujeres y derechos humanos luchan contra la "cultura del silencio". http://www.boell-latinoamerica. org/web/103-Feminicidios_en_M\%C3\%A9xico-1164. html (11 enero, 2013).

El Comercio. Pe. (2012, septiembre 26). Delito de feminicidio será castigado hasta con cadena perpetua en el país. http://elcomercio.pe/actualidad/1475123/noticia-delito-feminicidio-castigado-hasta-cadena-perpetua-pais (30 septiembre, 2012).

El Tiempo (2012, 24 noviembre). En el 2012, 47 mil afectadas por violencia intrafamiliar. Redacción justicia. http:// www.eltiempo.com/justicia/ARTICULO-WEB-NEW_ NOTA_INTERI OR12399406.HTML (16 diciembre, 2012).

España. Tribunal Constitucional. Sentencia TC-59 (2008, mayo 14). http://online.lexnova.es/servicesLXOL/viso rdoc? signatura $=5$ A713E29816FAF638C9C12E4666BE B62\&titulacion $=(5$ enero, 2013) .

G. Atencio \& E. Laporta. Publicaciones etiquetadas con Ciudad Juárez. Tipos de feminicidio o las variantes de la violencia extrema patriarcal. http://antropologiadegenero.com/?tag=ciudad-juarez (31 diciembre, 2012).

G. Atencio. Feminicidio-femicidio: un paradigma para el análisis de la violencia de género. http://www.feminicidio. net/index.php?option=com_content\&view $=$ article\&id $=67 \&$ Itemid $=8$ (23 septiembre, 2012).

G. I. Ramírez. Proyecto de ley "Rosa Elvira Cely" No. 49 del 2012-Senado. VillamilMartínezCristina(2012, agosto24). Atención ciudadana Congreso. Re: PL: 49/2012 S. https:// exchange.camaradirecta.com/owa/?ae=Item\&t=IPM. Note\&id=RgAAAAAU1llVX9B5QJJqYVFVk1C5BwAF KQnbTl0aQYV8pT0F4ZYfAAAStAq6AAAFKQnbTl0a
QYV8pT0F4ZYfAAASuQ\%2frAAAJ (24 agosto, 2012). Guatemala. Decreto 22-2008.

Instituto Nacional de Medicina Legal (INML). Forensis. Homicidio, capítulo 2. Aproximaciones a los conceptos de femicidio, feminicidio $y$ homicidio en mujeres. http:// www.medicinalegal.gov.co/images/stories/root/FORENSIs/2009/Homicidios.pdf (25 abril, 2011).

J. E. Monárrez. Peritaje sobre feminicidio sexual sistémico en Ciudad Juárez. Caso 12.498. "González y otras vs México". Campo Algodonero. http://www.corteidh.or.cr/ docs/casos/expedientes/Mon\%C3\%A1rrez.pdf. (31 diciembre, 2012).

J. Monárrez. Feminicidio sexual serial en Ciudad Juárez. Debate Feminista, año 13, Vol. 25, abril 2002.

L. M. Cabrera. Informe de la Mesa por el derecho de las mujeres a una vida libre de violencias sobre la implementación de la ley 1257 del 2008 y su estado actual de cumplimiento. Corporación Sisma Mujer. http://www.sismamujer. $\mathrm{org} /$ sites/default/files/publicaciones/1\%C2\%B0\%20 Informe\%20Mesa\%201257..pdf (15 septiembre, 2012).

L.Y. Forero. Muerte de mujeres en manos de su pareja o ex pareja íntima, según departamentos Colombia 2007-2011. https://exchange.camaradirecta.com/ owa $/$ ? ae $=$ Item \& $\mathrm{t}=$ IPM.Note\&id=RgAAAAAU11lVX9B5QJJqYVFVk1C5BwBXqC4UUMJ4QYLLAlJg\%2bsfHAAfiFS\%2bLAAAXvcxBXlPATpPTPoamv9WgAAAABBVkAAAJ (19 julio, 2012).

M. González. Mujeres fallecidas por femicidio en Costa Rica, bajo el ámbito de la ley de penalización de la violencia contra las mujeres y la aplicación de la Convención Internacional Belém do Pará y CEDAw durante el 2011. www.poder-judicial.go.cr/planificacion/Informes.../ 164-PLA-2012.rtf. (11 septiembre, 2012).

M. Santibáñez \& T. Vargas (2011). Reflexiones en torno a las modificaciones para sancionar el femicidio y otras reformas relacionadas (Ley No. 20.480). Revista Chilena de Derechos vol. 38 núm. 1. Santiago. http://www.scielo.cl/ pdf/rchilder/v38n1/art13.pdf. (30 octubre, 2012).

Mecanismo de Seguimiento de la Convención de Belém do Pará (MESECvi). Legislación sobre Femicidio. Segundo Informe Hemisférico sobre la Implementación de la Convención de Belém do Pará. oEA. (2012).

N. García. Colombia: Feminicidio Invisible. http://antropologiadegenero.com/?p=4455- (23 septiembre, 2012).

O. Sánchez Gómez. ¿Será que a las mujeres nos matan porque nos aman? Feminicidios en Colombia 2002-2009. http:// www.casmujer.org/index.php/wf-menucpanel/publicaciones/ítem/sera-que-a-las-mujeres-nos-matan-porquenos-aman-feminicidios-en-colombia-2002-2009.html?category_id=13. (11 septiembre, 2012). 
Organización de las Naciones Unidas. Femicidio en Chile. http:// www.onu.cl/pdfs/fenicidio.pdf (23 septiembre, 2012).

P. Toledo. El derecho penal frente a la violencia contra las mujeres. Feminicidio. Consultoría para la oficina en México del Alto Comisionado de las Naciones Unidas para los derechos humanos. México: OACNUdH. (2009).
R. Martínez. Pautas vigencia 2012 servicio pospenitenciario. http://www.inpec.gov.co/portal/page/portal/Inpec/ InstitucionINPEC/PlanesInstitucionales/ReinsercionSocial (13 octubre, 2012).

S. Bringas. Feminicidio ¿necesidad de sexualizar el derecho penal? A propósito de la Ley No. 29.819. pág. 3. http:// www.derechoycambiosocial.com/revista028/Feminicidio.pdf (22 septiembre, 2012). 